\title{
Cesium Eluate Evaporation Solubility and Physical Property Behavior
}

September 9, 2002

Westinghouse Savannah River Company Savannah River Site Aiken, SC 29808 
This document was prepared in conjunction with work accomplished under Contract No. DE-AC09-96SR18500 with the U. S. Department of Energy.

\section{DISCLAIMER}

This report was prepared as an account of work sponsored by an agency of the United States Government. Neither the United States Government nor any agency thereof, nor any of their employees, makes any warranty, express or implied, or assumes any legal liability or responsibility for the accuracy, completeness, or usefulness of any information, apparatus, product or process disclosed, or represents that its use would not infringe privately owned rights. Reference herein to any specific commercial product, process or service by trade name, trademark, manufacturer, or otherwise does not necessarily constitute or imply its endorsement, recommendation, or favoring by the United States Government or any agency thereof. The views and opinions of authors expressed herein do not necessarily state or reflect those of the United States Government or any agency thereof.

This report has been reproduced directly from the best available copy.

Available for sale to the public, in paper, from: U.S. Department of Commerce, National Technical Information Service, 5285 Port Royal Road, Springfield, VA 22161, phone: (800) 553-6847, fax: (703) 605-6900

email: orders@ntis.fedworld.gov

online ordering: http://www.ntis.gov/help/index.asp

Available electronically at http://www.osti.gov/bridge

Available for a processing fee to U.S. Department of Energy and its contractors, in paper, from: U.S. Department of Energy, Office of Scientific and Technical Information, P.O. Box 62, Oak Ridge, TN 37831-0062,

phone: (865)576-8401,

fax: (865)576-5728

email: $\underline{\text { reports@ adonis.osti.gov }}$ 
WSRC-TR-2002-00411, Rev. 0

SRT-RPP-2002-00206

KEYWORDS:

River Protection Project Laboratory Cesium Eluate

Evaporation

Solubility

Physical Properties

RETENTION TIME:

0.1.1.1.1 Permanent

\title{
Cesium Eluate Evaporation Solubility and Physical Property Behavior
}

\author{
Authors: \\ R. A. Pierce, 773-A, SRTC, SRS \\ A. S. Choi, 773-42A, SRTC, SRS
}

Issue Date:

September 9, 2002

Test Specification No.

24590-WTP-TSP-RT-01-009, Rev. 0

Test Plan No.

WSRC-TR-2001-00508, Rev. 0

Test Scoping Statement: $\quad$ S-78

Westinghouse Savannah River Company

Savannah River Site

Aiken, SC 29808

Prepared for the U.S. Department of Energy Under Contract Number DE-AC09-96SR18500

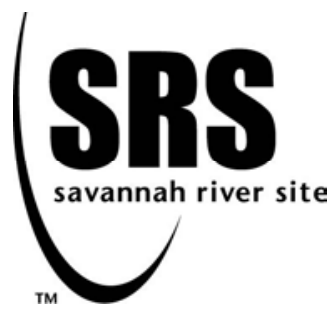


WSRC-TR-2002-00411, Rev. 0

SRT-RPP-2002-00206

Completeness of Testing

This report describes the results of work and testing specified by 24590-WTPTSP-RT-01-009, Rev. 0 and WSRC-TR-2001-00508, Rev. 0. . The performed work followed established quality assurance requirements and was conducted as authorized. The descriptions provided in this test report are an accurate account of both the conduct of the work and the data collected. Results required by the test plan are reported. Also reported are any unusual or anomalous occurrences that are different from starting hypotheses. The test results and this report have been reviewed and verified. 


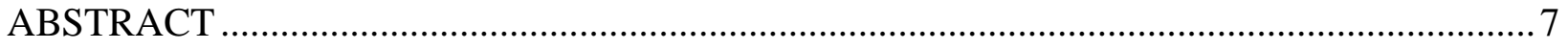

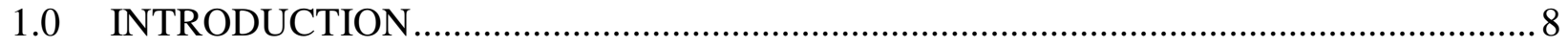

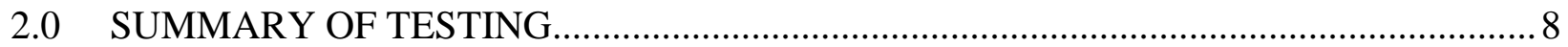

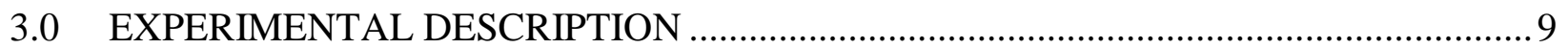

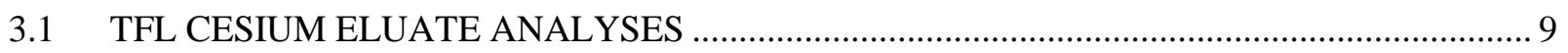

3.2 Modeling of AZ-102 TFL Cs Eluate Evaporation ………………………………………….... 9

3.2.1 Semi-Batch Evaporation Model ................................................................................................. 10

3.2.2 AZ-102 TFL Cesium Eluate …………………………………………………………………. 10

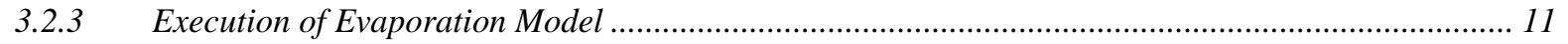

3.3 SYSTEM CONFIGURATION …………………………………………………..... 11

3.4 EVAPORATION EXPERIMENT \#1 …………………………………………………...... 13

3.5 EVAPORATION EXPERIMENT \#2 …………………………………………………... 14

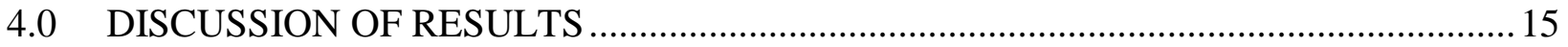

4.1 EXPERIMENTAL DATA - EVAPORATOR CONCENTRATE …………………………….... 15

4.2 SOLUBILITY - EVAPORATOR CONCENTRATE ……………………………………..... 18

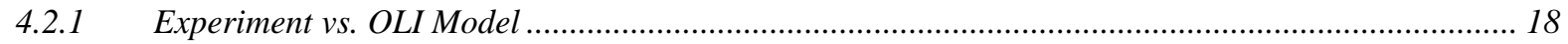

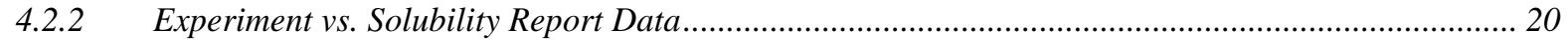

4.3 PHYSICAL PROPERTIES - EVAPORATOR CONCENTRATE ............................................ 21

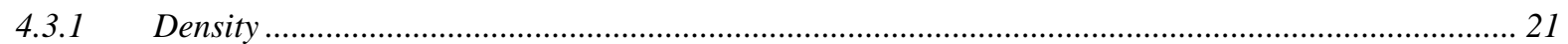

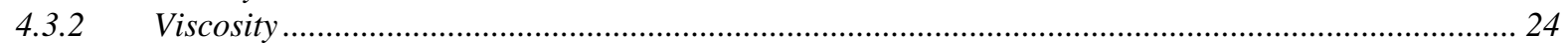

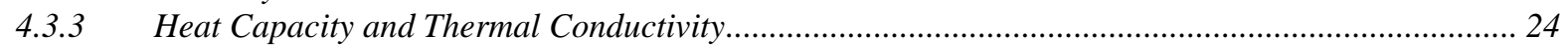

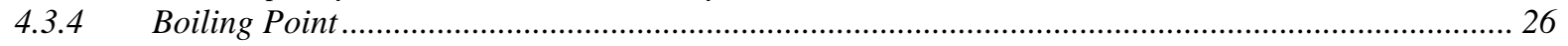

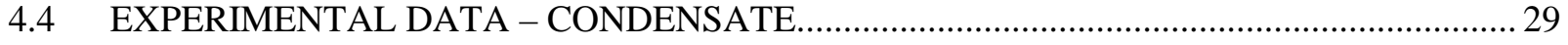

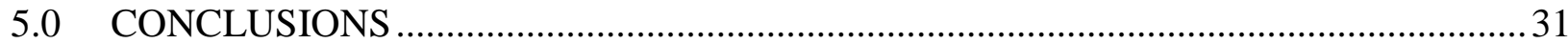

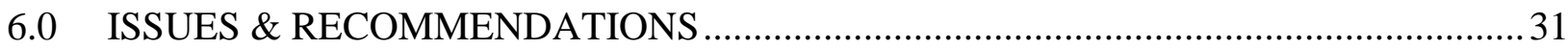




\section{LIST OF FIGURES}

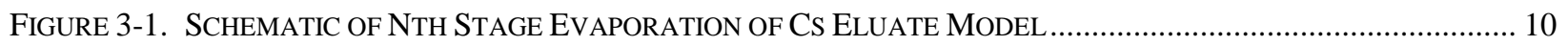

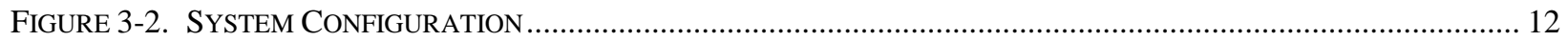

FIGURE 3-3. EVAPORATION EQUIPMENT IN CHEMICAL HOOD ……............................................................... 13

FIGURE 4-1. INCREASING CR CONCENTRATION IN EVAPORATOR CONCENTRATE ................................................... 17

FiguRE 4-2. OLI MOdEL PREDICTION VS. EXPERIMENTAL DATA ....................................................................... 20

FIGURE 4-3. EXPERIMENTAL DATA COMPARED TO SODIUM NITRATE SOLUBILITY .................................................. 21

FigURE 4-4. TFL AZ-102 CESIUM ELUATE EVAPORATION DENSITY ..................................................................... 22

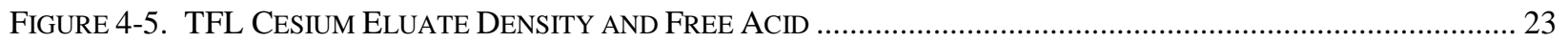

FIGURE 4-6. OLI MOdEL DENSITY PREDICTION VS. EXPERIMENTAL DATA ............................................................. 23

FIGURE 4-7. EXPERIMENTAL DENSITY DATA AND DENSITY DATA MATRIX ……................................................. 24

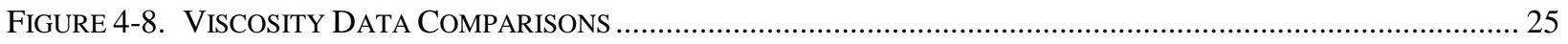

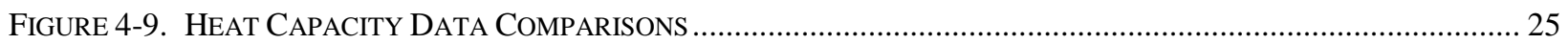

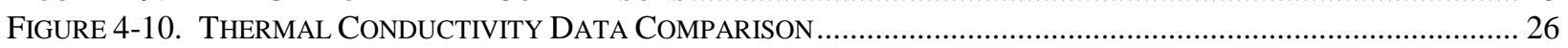

FIGURE 4-11. METHOD VALIDATION AND LITERATURE VALUES ....................................................................... 27

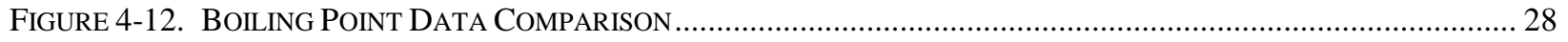

\section{LIST OF TABLES}

TABLE 3-1. TFL AZ-102 Cesium Eluate CoMPosition.................................................................................... 9

TABle 3-2. COMPosition of AZ-102 TFL Cs Eluate FeEd For SEMI-BATCh EVAPORATION MOdEL .................... 11

TABLE 3-3. EXPERIMENT \#2 EVAPORATOR POT VOLUME PROFILE .................................................................... 14

TABLE 4-1. EXPERIMENT \#1 EVAPORATOR CONCENTRATE DATA................................................................... 16

TABLE 4-2. EXPERIMENT \#2 EVAPORATOR CONCENTRATE DATA........................................................................ 16

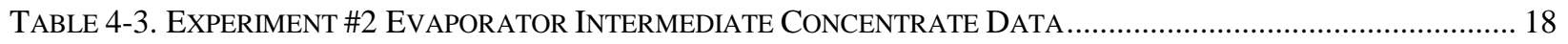

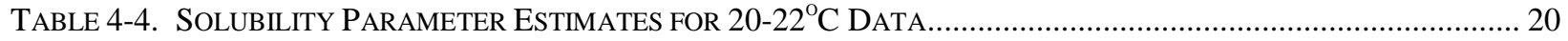

TABLE 4-5. SUMMARY OF PREDICTED AND MEASURED PHYSICAL PROPERTY DATA …........................................... 21

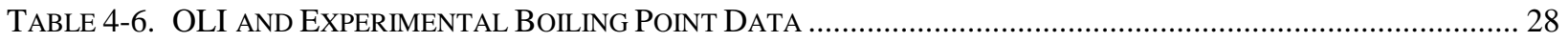

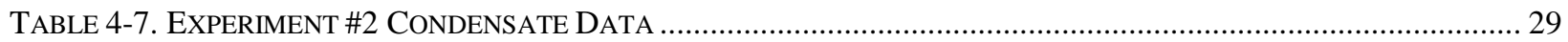

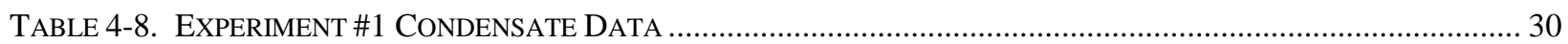

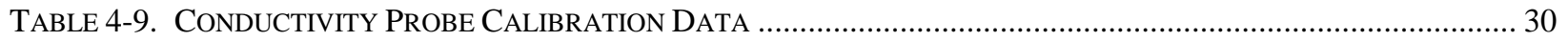

\section{LIST OF ACRONYMS}

$\begin{array}{ll}\text { AA } & \text { Atomic Absorption } \\ \text { IC } & \text { Ion Chromatography } \\ \text { ICPES } & \text { Inductively Coupled Plasma Emissions Spectroscopy } \\ \text { LAW } & \text { Low Activity Waste } \\ \text { RPP } & \text { River Protection Project } \\ \text { SRTC } & \text { Savannah River Technology Center } \\ \text { TOC } & \text { Total Organic Carbon } \\ \text { TIC } & \text { Total Inorganic Carbon } \\ \text { WTP } & \text { Waste Treatment Plant } \\ \text { XRD } & \text { X-ray Diffraction }\end{array}$




\section{WSRC-TR-2002- 00411, Rev. 0 \\ SRT-RPP-2002-00206}

\section{ABSTRACT}

The baseline flowsheet for low activity waste (LAW) in the Hanford River Protection Project (RPP) Waste Treatment Plant (WTP) includes pretreatment of supernatant by removing cesium using ion exchange. When the ion exchange column is loaded, the cesium will be eluted with a $0.5 \mathrm{M}$ nitric acid $\left(\mathrm{HNO}_{3}\right)$ solution to allow the column to be conditioned for re-use. The cesium eluate solution will then be concentrated in a vacuum evaporator to minimize storage volume and to recycle $\mathrm{HNO}_{3}$.

Two experiments were performed with a TFL-generated AZ-102 cesium eluate simulant. The data from the experiment was compared with predictions from the OLI model. The predictions of the OLI model show good agreement with experimental results. A plot of the OLI predictions with earlier solubility data showed excellent agreement between the model and experimental data. For the evaporation test, the OLI model predicted precipitation of $\mathrm{NaNO}_{3}$ at a concentration factor of 50. Evaporation experiments yielded bulk precipitation of $\mathrm{NaNO}_{3}$ at a concentration factor of 51-55. Trace amounts of precipitate formed at concentration factors of 41-45 and 46-50 after several days. The difference between the model results and the evaporation data can be attributed to wide fluctuations in measured total acidity for the evaporation test. The cause of the total acid fluctuations is unknown.

OLI model predictions of condensate acidity, boiling point, and sample density agree with experimental data. The experimental data exhibits a local minimum at a concentration factor of 25-30 that is not predicted by the model. The local minimum in the density data corresponds with the reduction of free acid (relative to total acid) in the system and an apparent change in boiling point behavior. Viscosity predictions by OLI show some agreement with experimental data. The modeling data exhibit a trend comparable to experimental, but the absolute viscosity values for the OLI data are somewhat higher than the measured viscosity data. The reason for the difference is unknown.

A comparison of the evaporation data with earlier solubility and physical property studies also show good agreement. These comparisons predict that a precipitate can form, based on the experimental data, at a concentration factor of 41-45. Density and viscosity data from the evaporation also agree with earlier physical property data. Heat capacity and thermal conductivity data exhibit significant discrepancies.

The evaporation experiments also demonstrated the performance of a conductivity probe in analyzing samples for acid concentration. Throughout the experiments the conductivity probe was accurate and reliable. In spite of fluctuations in condensate acidity throughout testing, calculated averages shows excellent agreement with the measured samples. The conductivity probe has the added benefit of being a simple analysis method with little or no opportunity for operator error. No resin fines were observed in the TFL AZ-102 eluate fed to the evaporator. Foaming problems were not encountered during evaporation.

Fluctuations in total acid measurements make it difficult to correlate experimental data with OLI model. Both the OLI model prediction and the evaporation experiment agree with earlier solubility data without producing identical evaporation behavior. It is not clear if the fluctuations are a product of experimental technique or chemical behavior. In addition to the fluctuations, attempts to perform a material balance around total acid show that the measurement of total acid does not agree with what is expected based on condensate acidity. No definitive explanation is available, but it is expected that the formation of cation complexes with acid greatly affect the solubility behavior of the system.

Because of the importance of confirming the performance of the OLI model, it is recommended that several additional semi-batch evaporation tests be performed. These can be conducted as part of Test Scoping Statements S-82 and S-86. 


\section{WSRC-TR-2002- 00411, Rev. 0 \\ SRT-RPP-2002-00206}

\subsection{INTRODUCTION}

The baseline flowsheet for low activity waste (LAW) in the Hanford River Protection Project (RPP) Waste Treatment Plant (WTP) includes pretreatment of supernatant by removing cesium using ion exchange. When the ion exchange column is loaded, the cesium will be eluted with a $0.5 \mathrm{M}$ nitric acid $\left(\mathrm{HNO}_{3}\right)$ solution to allow the column to be conditioned for re-use. The cesium eluate solution will then be concentrated in a vacuum evaporator to minimize storage volume and recycle $\mathrm{HNO}_{3}$. To prevent the formation of solids during storage of the evaporator bottoms, criteria have been set for limiting the concentration of the evaporator product to $80 \%$ of saturation at $25^{\circ} \mathrm{C}$.

Prior work has collected fundamental data for predicting solubility and other physical property measurements. ${ }^{1}$ Other ongoing efforts have involved the development of a computer model to predict solubility and physical properties during evaporation. ${ }^{2}$ Evaporation experiments were conducted with cesium eluate simulant generated from a pilot scale experiment in the Thermal Fluids Lab (TFL) at the Savannah River Technology Center (SRTC). The data from the experiments will be used to validate the modeling data.

This report completes the activities of Section 3.4 of the Task Technical and Quality Assurance Plan for Evaluating the Evaporation Behavior of Cs Eluate (WSRC-TR-2001-00508). Section 3.2 of the TTQAP addresses laboratory evaporation experiments using TFL (Thermal Fluids Lab) Cs eluate simulant.

\subsection{SUMMARY OF TESTING}

SRTC obtained eluate solutions from the Pilot Scale Ion ExchangeTesting for use in a bench-scale evaporation experiment. SRTC researchers designed a bench scale evaporation unit to evaporate the simulated eluate from Pilot Scale Ion Exchange Testing. The cesium eluate simulant was created in the pilot tests using an AZ-102 tank simulant. SRTC personnel characterized the cesium eluate.

Based on the eluate characterization, the OLI evaporation model predicted the evaporation endpoint and operating conditions. A laboratory-scale evaporator was designed for semi-continuous operation and offgas collection under vacuum conditions. A conductivity meter was used in conjunction with the experiment for correlation with overhead condensate nitric acid concentrations. It should be noted that the bench scale unit did not include a reflux column, or rectifier, because the overheads can be withdrawn at the appropriate concentration without a rectifier.

Testing included the following activities:

1. Predict Evaporator Behavior: The data collected from previous experiments was used to predict the evaporator behavior. The information in the OLI evaporation model was also used to predict the evaporator behavior for the simulant.

2. Perform Evaporator Experiments: Two experiments were performed with the simulant from the Pilot Scale Ion Exchange Testing program. The experimental evaporator was operated at constant volume with the capability to periodically removing liquid samples. Eluate feed rate to the evaporator was controlled to match the condensate volume in a near-continuous manner.

The first experiment helped gain operating experience and identify the evaporation endpoint. The second test was used to collect five intermediate process samples for analysis of physical and chemical properties. The evaporator condensate was monitored for nitric acid concentration with an at-line unit that measured conductivity.

\footnotetext{
${ }^{1}$ R. A. Pierce and T. B. Edwards, “Cesium Eluate Evaporation Solubility and Physical Property Behavior,” WSRCTR-2002-00273, dated June 11, 2002.

${ }^{2}$ Reference from Alex Choi
} 
3. Analyze Process Samples: The bulk solubility at $25+0 /-5{ }^{\circ} \mathrm{C}$ for each simulant was measured using cation and anion concentration analyses. Both the concentrate and condensate were analyzed. The starting, intermediate, and final samples were analyzed for heat capacity, thermal conductivity, liquid density, viscosity, cations (inductively coupled plasma emission spectroscopy [ICPES] and atomic absorption [AA]), anions (ion chromatography $[\mathrm{IC}])$, free acid, total acid, and total organic carbon. The exception to these is that the viscosity, thermal conductivity, and heat capacity for evaporator condensates were not required. Because a significant quantity of organic was detected during total organic carbon (TOC) analysis from the first evaporation test, samples of the eluate solutions were submitted for volatile and semi-volatile organic analysis (VOA and SVOA).

4. Compare and Correlate Experimental Data: SRTC used the experimental data to compare it with the predictions provided by the OLI model. The data was also compared with the data developed during earlier solubility testing. ${ }^{3}$

\subsection{EXPERIMENTAL DESCRIPTION}

\subsection{TFL CESIUM ELUATE ANALYSES}

A 25-liter sample of cesium eluate simulant was received from the TFL Pilot Scale Ion ExchangeTesting. The eluate received from TFL was comprised only of solution from cesium elution - the sample did not contain any portion of the column rinse solutions. The sample was analyzed for cations (ICPES and AA), anions (IC), total and free acid (autotitrator), density, total organic and inorganic carbon, volatile organic compounds, and semi-volatile organic compounds. No resin fines were observed in the TFL AZ-102 eluate. The data are listed in Table 3-1. The results were used to predict evaporator behavior.

Table 3-1. TFL AZ-102 Cesium Eluate Composition

\begin{tabular}{|c|c|c|c|c|}
\hline \multicolumn{5}{|c|}{ TFL AZ-102 FEED } \\
\hline & $(\mathrm{mg} / \mathrm{L})$ & Cation mole \% & & $(\mathrm{mg} / \mathrm{L})$ \\
\hline $\mathrm{Na}$ & 1520 & 11.25 & S (ICPES) & 13.4 \\
\hline $\mathrm{Al}$ & 3.70 & 0.01 & & \\
\hline$\overline{\mathrm{Ca}}$ & 5.43 & 0.01 & NO3 & 34000 \\
\hline $\mathrm{Cr}$ & 59.3 & 0.17 & $\mathrm{~F}$ & $<20$ \\
\hline $\mathrm{Cu}$ & 2.88 & 0.00 & $\mathrm{Cl}$ & $<20$ \\
\hline $\mathrm{Fe}$ & 5.18 & 0.01 & $\mathrm{SO} 4$ & 33 \\
\hline $\mathrm{K}$ & 25.8 & 0.11 & $\mathrm{PO} 4$ & $<100$ \\
\hline$\overline{C s}$ & 7.41 & 0.00 & $\mathrm{C} 2 \mathrm{O} 4$ & $<100$ \\
\hline Total Acid (M) & 0.52 & 88.47 & TOC & 52.8 \\
\hline Free Acid (M) & 0.52 & & TIC & 11.5 \\
\hline Density (g/cc) & 1.0198 & & & \\
\hline
\end{tabular}

\subsection{Modeling of AZ-102 TFL Cs Eluate Evaporation}

According to the WTP pretreatment flowsheet, the cesium eluate will be concentrated in a reboiler with thermosiphon circulation to reduce the volume. The eluate is fed to the reboiler pot initially charged with a concentrated acid, and the vacuum is adjusted so that boilup would occur at $50{ }^{\circ} \mathrm{C}$ while maintaining a constant liquid volume in the pot. The feeding is to continue with no bottom removal until the liquid in the pot reaches the target endpoint of $80 \%$ saturation with respect to any one of the major salts present. Since the acidity in the pot continuously changes throughout the evaporation process, so does the vapor-liquid equilibrium (VLE) of nitric acid. This section

\footnotetext{
${ }^{3}$ R. A. Pierce and T. B. Edwards. "Cesium Eluate Evaporation Solubility and Physical Property Behavior," WSRCTR-2002-00273, dated June 11, 2002.
} 


\section{WSRC-TR-2002- 00411, Rev. 0 \\ SRT-RPP-2002-00206}

describes how this semi-batch evaporation process was modeled using the Environmental Simulation Program (ESP) licensed by OLI Systems, Inc.

\subsubsection{Semi-Batch Evaporation Model}

The ESP software has a module, called DynaChem, used to simulate dynamic processes. However, its use as a fullscale dynamic flowsheet simulator is rather limited, since it provides three built-in "units" that can be used to model only a certain number of unit operations and does not allow users to build custom models. As a result, the main steady state module of the ESP software was used in this study to model the semi-batch evaporator by approximating it as a series of continuous still pots, as shown in Figure 1. The mass ratio of the initial acid chargeto-cesium eluate feed to the $1^{\text {st }}$ stage was set at 5:1. Additional stages were then added to the existing model one-byone at the same feed ratio of 5:1, until the concentrate from the final stage reaches the prescribed evaporation endpoint at $25^{\circ} \mathrm{C}$ and $1 \mathrm{~atm}$. Higher feed ratios of 10:1 and 100:1 were also tried and they were shown to have little impact on the overall vapor-liquid equilibria; only the required number of stages was increased proportionally. The validity of approximating the semi-batch evaporator as a series of continuous still pots was confirmed earlier against the batch distillation data collected at $1 \mathrm{~atm}^{4}$

Figure 3-1. Schematic of Nth Stage Evaporation of Cs Eluate Model

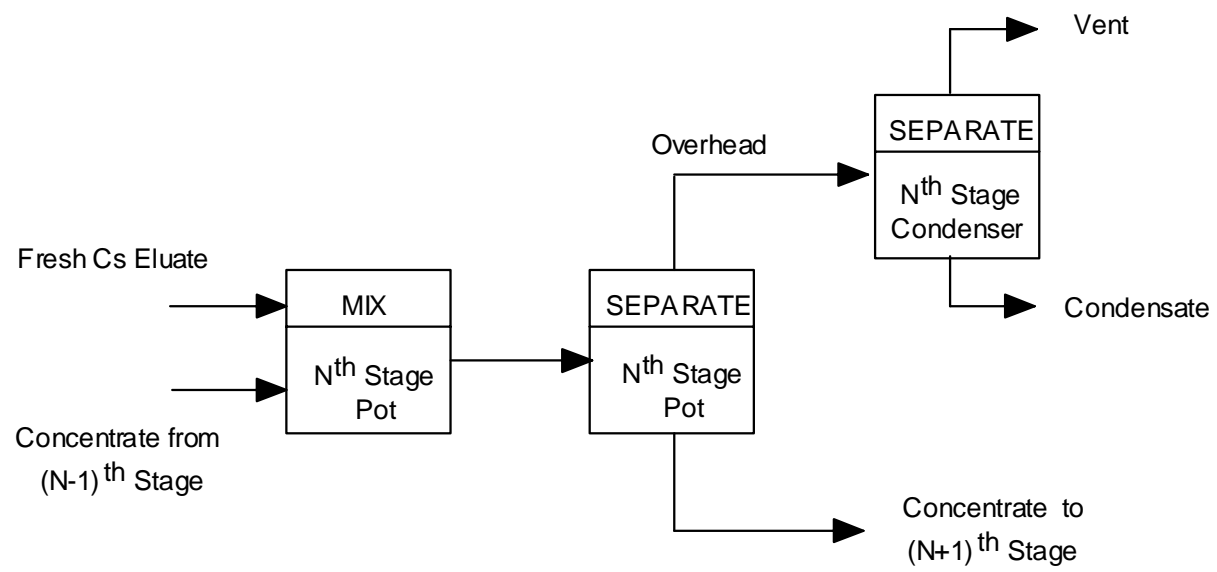

\subsubsection{AZ-102 TFL Cesium Eluate}

A pilot-scale cesium ion-exchange demonstration run was made recently at the Thermal Fluids Lab (TFL) using the Tank 241-AZ-102 simulant. The loaded columns were eluted with 0.5 molar nitric acid, and the resulting eluate solution formed the basis for the feed chemistry of the semi-batch evaporation model. Table 3-2 shows the analytical data for the AZ-102 cesium eluate sample and the resulting eluate composition in a neutral species form. The concentrate of nitrate ion shown reflects a $7 \%$ increase over the measured value to preserve the charge balance. The actual input to the semi-batch evaporator model were the full-scale flow rates given in the far right-hand column of Table 3-2. These flow rates were set based on the instantaneous flow rate of sodium required to meet the design basis LAW glass production rate and the sodium-to-cesium mass ratio found in the untreated AZ-102 filtrate. ${ }^{5}$ Based on the design basis Envelope B glass production rate of 60 metric tons per day at $10 \mathrm{wt} \% \mathrm{Na}_{2} \mathrm{O}$, the required instantaneous flow rate of sodium in the AZ-102 supernate was calculated to be $185,484 \mathrm{~g} / \mathrm{hr}$. The corresponding instantaneous flow rate of cesium was then calculated to be $119.14 \mathrm{~g} / \mathrm{hr}$ based on the sodium-to-cesium mass ratio of

\footnotetext{
${ }^{4}$ Choi, A. S., "Estimation of Physical Properties of AN-107 Cesium and Technetium Eluate Blend", WSRC-TR2000-00527, Westinghouse Savannah River Co., Aiken, SC, Feb. 2001.

${ }^{5}$ Hassan, N. M. et al, "Small-Scale Ion Exchange Removal of Cesium and Technetium from Envelope B Hanford Tank 241-AZ-102”, WSRC-TR-2000-00419, Rev. 0, Westinghouse Savannah River Co., Aiken, SC, Jan. 2001.
} 


\section{WSRC-TR-2002- 00411, Rev. 0 \\ SRT-RPP-2002-00206}

1,557, which was estimated from the SRTC analytical data. Therefore, the full-scale flow rates given in Table 3-2 represent the required instantaneous flow rates of individual cesium eluate components to support the design basis Envelope B glass production rate.

Table 3-2. Composition of AZ-102 TFL Cs Eluate Feed for Semi-Batch Evaporation Model

\begin{tabular}{|c|c|c|c|c|c|c|c|c|c|}
\hline Anions & $\mathrm{FW}$ & Conc (mg/l) & Conc (M) & Equiv (M) & Species & MW & Conc (M) & g/liter & $\begin{array}{r}\text { full-scale flow } \\
(\mathrm{mole} / \mathrm{hr})\end{array}$ \\
\hline NO3 & 62 & 3.637E+04 & 5.867E-01 & 5.867E-01 & $\mathrm{NaNO} 3$ & 85 & 6.123E-02 & 5.2043 & 984.4211 \\
\hline $\mathrm{SO} 4$ & 98.058 & $3.300 \mathrm{E}+01$ & 3.365E-04 & 6.731E-04 & $\mathrm{Na} 2 \mathrm{SO} 4$ & 142.04 & 3.365E-04 & 0.0478 & 5.4109 \\
\hline $\mathrm{C} 2 \mathrm{O} 4$ & 88.02 & $1.936 \mathrm{E}+02$ & $2.200 \mathrm{E}-03$ & $4.400 \mathrm{E}-03$ & $\mathrm{Na} 2 \mathrm{C} 2 \mathrm{O} 4$ & 134 & $2.200 \mathrm{E}-03$ & 0.2948 & 35.3722 \\
\hline PO4 & 94.9714 & $2.085 E+00$ & 2.195E-05 & $6.586 \mathrm{E}-05$ & Na3PO4 & 163.944 & 2.195E-05 & 0.0036 & 0.3530 \\
\hline B4O7 & 155.24 & $1.120 \mathrm{E}+01$ & $7.216 \mathrm{E}-05$ & $1.443 \mathrm{E}-04$ & $\mathrm{Na2B} 4 \mathrm{O} 7$ & 201.22 & $7.216 \mathrm{E}-05$ & 0.0145 & 1.1601 \\
\hline $\mathrm{MoO} 4$ & 159.94 & 3.334E-01 & $2.085 \mathrm{E}-06$ & 4.169E-06 & $\mathrm{Na2MoO} 4$ & 205.92 & $2.085 \mathrm{E}-06$ & 0.0004 & 0.0335 \\
\hline Total Anions & & & 5.893E-01 & 5.919E-01 & & & & & \\
\hline \multicolumn{10}{|l|}{ Cations } \\
\hline $\mathrm{Na}$ & 22.99 & $1.520 \mathrm{E}+03$ & $6.612 \mathrm{E}-02$ & 6.612E-02 & & & & & \\
\hline $\mathrm{Al}$ & 26.98154 & $4.470 \mathrm{E}+00$ & 1.657E-04 & 4.970E-04 & $\mathrm{Al}(\mathrm{NO} 3) 3$ & 212.98154 & 1.657E-04 & 0.0353 & 2.6637 \\
\hline $\mathrm{Ba}$ & 137.33 & $7.500 \mathrm{E}-02$ & $5.461 \mathrm{E}-07$ & $1.092 \mathrm{E}-06$ & $\mathrm{Ba}(\mathrm{NO} 3) 2$ & 261.33 & $5.461 \mathrm{E}-07$ & 0.0001 & 0.0088 \\
\hline $\mathrm{Ca}$ & 40.08 & $5.430 \mathrm{E}+00$ & 1.355E-04 & $2.710 \mathrm{E}-04$ & $\mathrm{Ca}(\mathrm{NO} 3) 2$ & 164.08 & $1.355 \mathrm{E}-04$ & 0.0222 & 2.1783 \\
\hline $\mathrm{Cr}$ & 51.996 & $5.930 \mathrm{E}+01$ & $1.140 \mathrm{E}-03$ & $3.421 \mathrm{E}-03$ & $\mathrm{Cr}(\mathrm{NO} 3) 3$ & 186.00342 & $1.140 \mathrm{E}-03$ & 0.2121 & 18.3368 \\
\hline Cs & 134.52 & $7.410 \mathrm{E}+00$ & $5.508 \mathrm{E}-05$ & $5.508 \mathrm{E}-05$ & CsNO3 & 196.52 & $5.508 \mathrm{E}-05$ & 0.0108 & 0.8857 \\
\hline $\mathrm{Cu}$ & 63.546 & $2.880 \mathrm{E}+00$ & $4.532 \mathrm{E}-05$ & $9.064 \mathrm{E}-05$ & $\mathrm{Cu}(\mathrm{NO} 3) 2$ & 187.546 & 4.532E-05 & 0.0085 & 0.7287 \\
\hline $\mathrm{Fe}$ & 55.847 & $5.180 \mathrm{E}+00$ & $9.275 \mathrm{E}-05$ & 2.783E-04 & $\mathrm{Fe}(\mathrm{NO} 3) 3$ & 241.847 & $9.275 E-05$ & 0.0224 & 1.4913 \\
\hline $\mathrm{K}$ & 39.0983 & $3.090 \mathrm{E}+01$ & 7.903E-04 & 7.903E-04 & KNO3 & 101.0983 & 7.903E-04 & 0.0799 & 12.7069 \\
\hline $\mathrm{Mg}$ & 24.305 & $1.400 \mathrm{E}-01$ & $5.760 \mathrm{E}-06$ & $1.152 \mathrm{E}-05$ & $\mathrm{Mg}(\mathrm{NO} 3) 2$ & 148.305 & $5.760 \mathrm{E}-06$ & 0.0009 & 0.0926 \\
\hline $\mathrm{Mn}$ & 54.938 & $1.800 \mathrm{E}-01$ & $3.276 \mathrm{E}-06$ & $6.553 \mathrm{E}-06$ & $\mathrm{Mn}(\mathrm{NO} 3) 2$ & 178.938 & $3.276 \mathrm{E}-06$ & 0.0006 & 0.0527 \\
\hline $\mathrm{Si}$ & 28.0855 & $5.610 \mathrm{E}+00$ & 1.997E-04 & 3.995E-04 & $\mathrm{Si}(\mathrm{OH}) 4$ & 96.11498 & 1.997E-04 & 0.0192 & 3.2116 \\
\hline $\mathrm{Sr}$ & 87.62 & $2.300 \mathrm{E}-01$ & 2.625E-06 & $5.250 \mathrm{E}-06$ & $\mathrm{Sr}(\mathrm{NO} 3) 2$ & 211.62 & 2.625E-06 & 0.0006 & 0.0422 \\
\hline $\mathrm{H}+$ & 1 & $5.200 \mathrm{E}+02$ & $5.200 \mathrm{E}-01$ & $5.200 \mathrm{E}-01$ & HNO3 & 63 & $5.200 \mathrm{E}-01$ & 32.7600 & $8,360.7018$ \\
\hline \multirow[t]{2}{*}{ Total Cations } & & & $6.875 \mathrm{E}-02$ & 5.919E-01 & $\mathrm{H} 2 \mathrm{O}$ & 18.02 & $5.444 \mathrm{E}+01$ & 981.0219 & $8.7531 E+05$ \\
\hline & & & & & Total & & & $1,019.7600$ & $8.8474 \mathrm{E}+05$ \\
\hline
\end{tabular}

\subsubsection{Execution of Evaporation Model}

One key process constraint that must be adhered to during the execution of the model was to ensure that the liquid volume in the pot or the flow rate of concentrate from one stage to the next is maintained constant throughout the entire evaporation cycle. This was achieved in essence by controlling the boilup rate or the vacuum in the pot. It turned out that by maintaining the molar boilup rate very close to that of the feed it was possible to contain the maximum volume fluctuations within $\pm 2 \%$. The model was run at an initial pot acidity of $7.24 \mathrm{M}$.

The composition of concentrated eluate flow out of each stage was checked for presence of any solids, and of the two cases the evaporation simulation was continued until crystals of the major salt, $\mathrm{NaNO}_{3}$, first appeared in the pot. The ESP model was run in conjunction with a private OLI database, called HNO3DB, and PUBLIC v6.5. The private database, $\mathrm{HNO} 3 \mathrm{DB}$, was developed recently for the Na-K-Cs-Al- $\mathrm{HNO}_{3}-\mathrm{H}_{2} \mathrm{O}$ system using both SRTC and literature data.

\subsection{SYSTEM CONFIGURATION}

A schematic of the experimental setup is included in Figure 3-2. A picture of the evaporation and two condensers is shown in Figure 3-3. The evaporator, feed reservoir, mist eliminator, and condensers were fabricated in the SRTC Glass Shop. The evaporator is a 5-inch diameter glass vessel with a volume of $2200 \mathrm{~mL}$. Heating is supplied through a Fisher Scientific IR4100 infrared hot plate. The evaporator is wrapped with an insulation blanket and has glass beads in the bottom to act as boiling stones. Feed is drawn into the evaporator by the vacuum in the system and is regulated through a metering stopcock. The evaporator temperature is monitored using a Cole-Parmer Type $\mathbf{J}$ thermocouple and thermocouple readout. The evaporator pressure is measured using a calibrated Omega Engineering PX01C1-O20AI high-accuracy pressure transducer attached to an Omega DP41-E meter. The evaporator top is also equipped with an air bleed valve to control evaporator pressure. 
Condenser \#1 is a 4-inch diameter vessel that is approximately 19 inches tall. Cooling coils extend 12 inches down into the vessel. The liquid volume below the coils is $1200 \mathrm{~mL}$ and the volume below the gas inlet tube is $1400 \mathrm{~mL}$. Condenser \#1 is cooled using a Neslab RTE-211 chiller. Condensate is removed from the system using a Fluid Metering, Inc. Model QV Pump.

Condenser \#2 is a 4-inch diameter vessel that is approximately 14.5 inches tall. Cooling coils extend 13.5 inches down into the vessel. The liquid volume below the coils is $150 \mathrm{~mL}$ and the volume below the gas inlet tube is 300 $\mathrm{mL}$. Condenser \#2 is cooled using a Lauda E200 chiller. Condensate is removed from the system using a Fluid Metering, Inc. Model QV Pump.

Vacuum is pulled on the system using a Vacuubrand MZ 2C Pump. Condensate conductivity is measured using a YSI 3200 Conductivity Meter equipped with a YSI Type 3253 Glass Dip Cell. Titrations performed in the lab use $0.0104 \mathrm{M} \mathrm{NaOH}$ with endpoint determined using phenolphthalein.

Figure 3-2. System Configuration

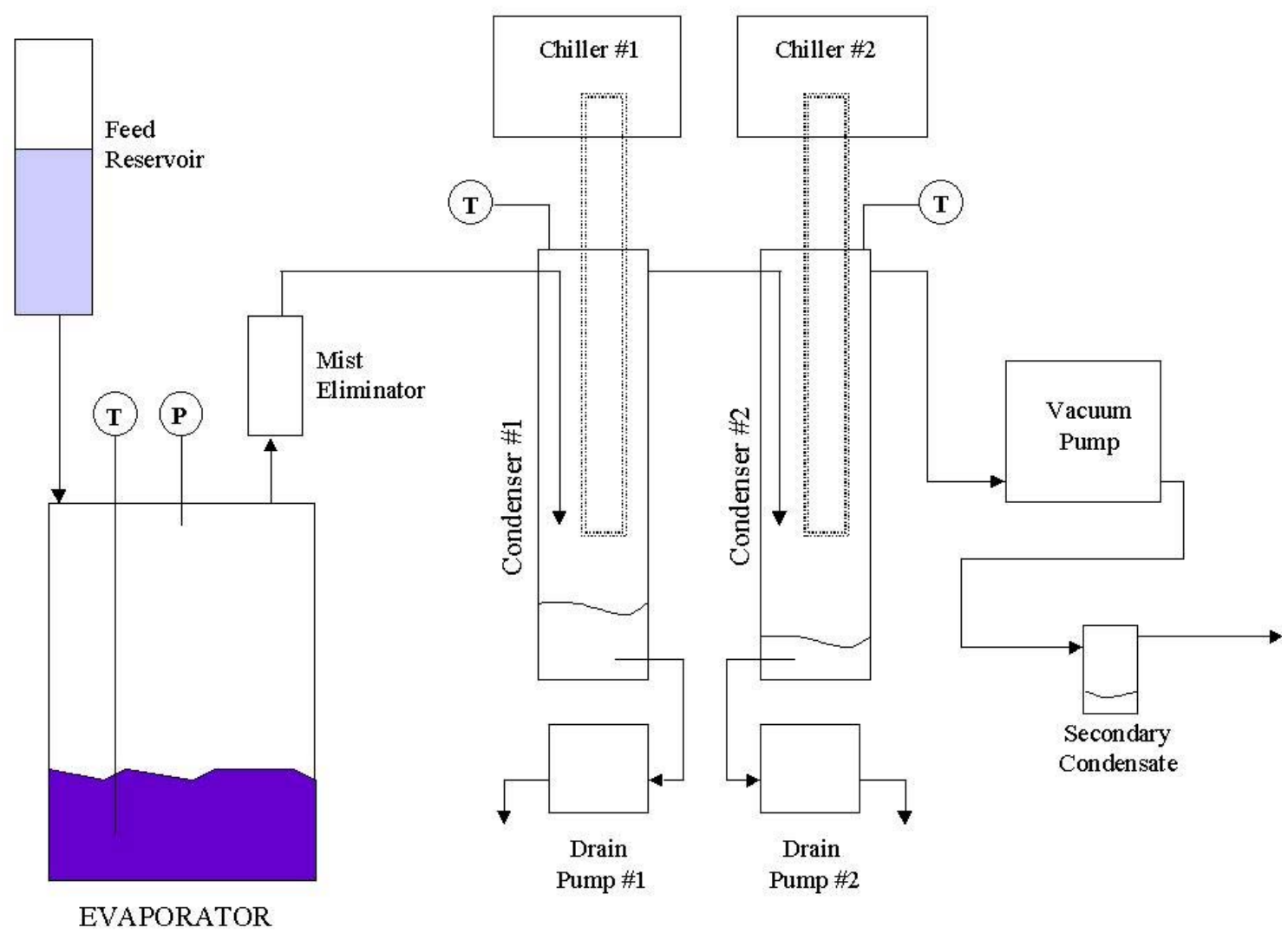




\section{WSRC-TR-2002- 00411, Rev. 0 \\ SRT-RPP-2002-00206}

Figure 3-3. Evaporation Equipment in Chemical Hood

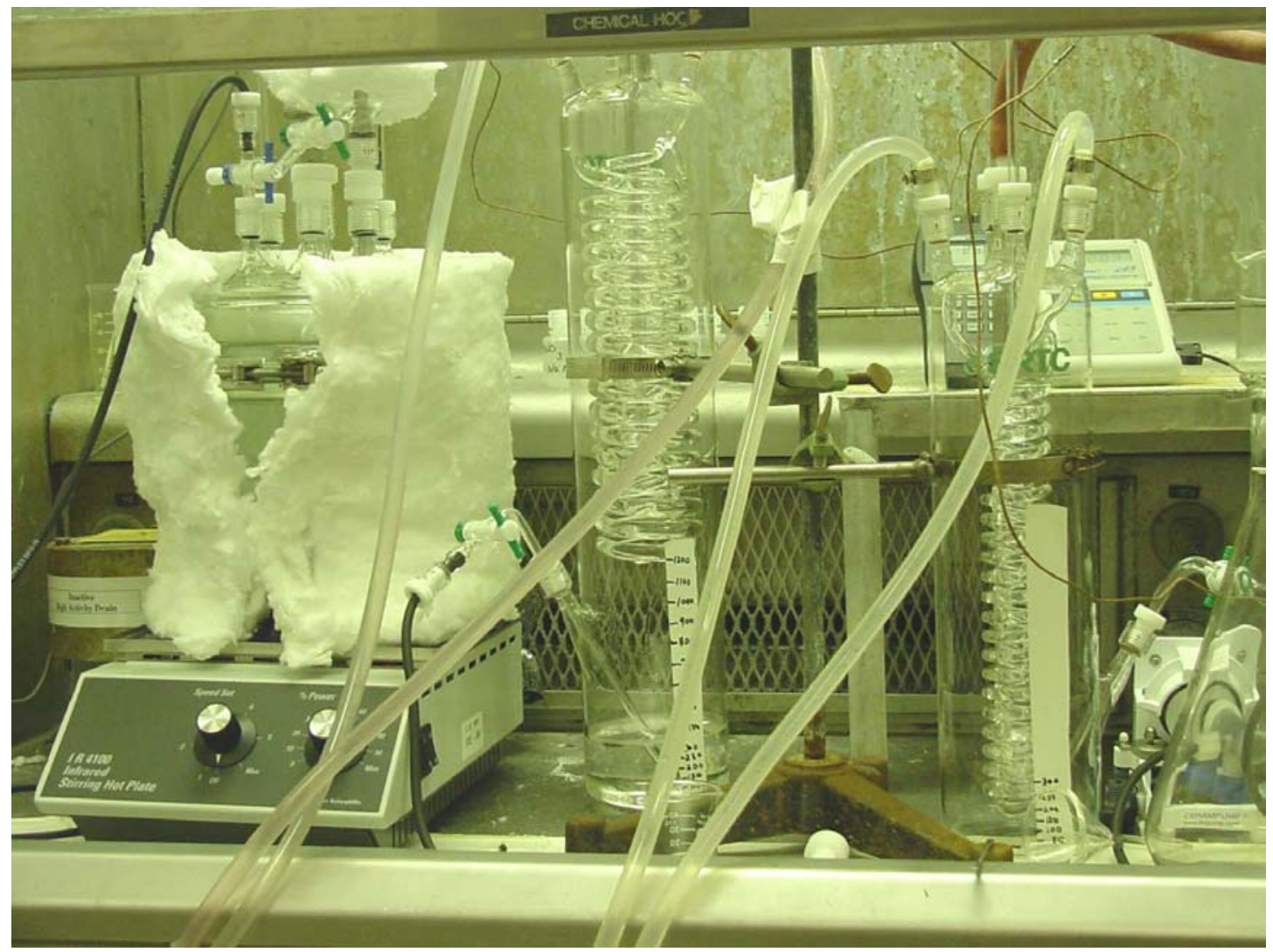

\subsection{EVAPORATION EXPERIMENT \#1}

In the first experiment, the evaporator was charged with $250 \mathrm{~mL}$ of $7.25 \mathrm{M} \mathrm{HNO}_{3}$. The pot was marked with a line to indicate the volume. The first chiller was set at $12^{\circ} \mathrm{C}$ and the second chiller operated at $5^{\circ} \mathrm{C}$. The chillers are operated at temperatures below the RPP design values in order to produced better mass balance data. The hot plate was turned on to approximately $50 \%$ and the evaporator was brought to boiling. Evaporator temperature was monitored using a thermocouple. The vacuum pump was then turned on and the pressure was regulated to $70+/-3$ torr. It was observed that the chiller to the Condenser \#1 limited the evaporation rate to about $12 \mathrm{~mL} / \mathrm{min}$. At higher evaporation rates, a system pressure of 70 torr could not be maintained. Feed was fed to the system at a rate sufficient to maintain a constant volume. There were no foaming problems encountered during evaporation.

The test was performed at a rate of 14 evaporator volumes per day - seven in the morning and seven in the afternoon. After each evaporator volume, the vacuum was removed from the system and the condensers were emptied. Any liquid in the mist eliminator was charged back into the evaporator. The evaporator liquid was allowed to cool to room temperature and observations were made for the presence of solids. The condensate for each evaporator volume was analyzed using the conductivity probe.

The conductivity probe was checked against three known $\mathrm{HNO}_{3}$ solutions $-0.262 \mathrm{M}, 0.524 \mathrm{M}$, and $0.774 \mathrm{M}-$ prior to the start of the test. The condensate from Condensers \#1 and \#2 were combined prior to analysis. At the end of the day, the condensate solutions for the full day (14 evaporator volumes) were combined into a single bottle and analyzed again for acidity. Condensate samples from each day were analyzed for cations (ICPES), anions (IC), and total organic and inorganic content (TIC/TOC). Secondary condensate was not retained because it was typically less than $2 \mathrm{~mL}$ per day.

After each seven evaporator volumes, boiling point data was collected. The system pressures was sequentially increased from 70 torr to $150+/-10$ torr and then to $300+/-25$ torr. At each pressure reading the system temperature 


\section{WSRC-TR-2002- 00411, Rev. 0 \\ SRT-RPP-2002-00206}

was allowed to stabilize while boiling was maintained. The evaporator pressure and temperature were recorded as the boiling point

After day four (56 evaporator volumes), solids were observed in the evaporator. Following precipitation in the evaporator pot, the solids were filtered at room temperature and analyzed using $\mathrm{x}$-ray diffraction (XRD). The liquid was analyzed for density, cations (ICPES and AA), anions, (IC) free and total acid, and carbon content (TIC/TOC).

\subsection{EVAPORATION EXPERIMENT \#2}

The second evaporation test was run in a manner similar to Test \#1. The evaporator pressure was 70+/-3 torr. The starting pot volume was $325 \mathrm{~mL}$ of $7.25 \mathrm{M} \mathrm{HNO}_{3}$. The evaporator pot was marked with a line to indicate the operating volume. As samples were withdrawn, the line was moved to reflect the adjusted volume. The first chiller was set at $20^{\circ} \mathrm{C}$ and second chiller operated at $5^{\circ} \mathrm{C}$. The chillers are operated at temperatures below the RPP design values in order to produced better mass balance data. The temperature of the first chiller was raised from $12^{\circ} \mathrm{C}$ in Experiment $\# 1$ to $20^{\circ} \mathrm{C}$ to reduce the thermal load on the first chiller. Since the condensate from both condensers is combined before analysis of acidity, the change has little impact on the overall data. The other primary controls were the evaporator pot and feed volumes. Temperatures in the evaporator pot and two condensers were monitored with thermocouples.

The test was performed at a rate of ten evaporator volumes per day - five in the morning and five in the afternoon. After each set of five evaporator volumes, the vacuum was removed from the system and the condensers were emptied. Any liquid in the mist eliminator was charged back into the evaporator. The evaporator volumes for the different stages of the test are listed in Table 3-3. During the test, $10 \mathrm{~mL}$ of sample was be removed immediately after the morning portion of the test, analyzed for density, and returned to the evaporator pot before testing in the afternoon. There were no foaming problems encountered during evaporation.

The conductivity probe was once again checked against three known $\mathrm{HNO}_{3}$ solutions $-0.262 \mathrm{M}, 0.524 \mathrm{M}$, and $0.774 \mathrm{M}$ - prior to analysis of condensate samples. The condensate from Condensers \#1 and \#2 were combined prior to analysis. The condensate for the morning portion of the test was analyzed for conductivity and stored. At the end of the afternoon portion of the test, the condensate was once again analyzed and stored. Secondary condensate from each day was also collected and stored.

At the appropriate time, samples were removed and stored for multiple analyses. These occurred after the processing of 10, 20,30,40,45, and 50 process volumes according to Table 3-3 - the sample corresponding to 45 process volumes was not submitted for analysis. After the samples were removed, the feed and pot control volumes were adjusted to compensate for the withdrawn sample. Upon cooling, these samples were inspected for solids. The evaporation sequence was continued until precipitation was observed in the evaporator bottoms sample that had cooled to room temperature.

Table 3-3. Experiment \#2 Evaporator Pot Volume Profile

\begin{tabular}{|c|c|c|c|}
\hline $\begin{array}{c}\text { Process } \\
\text { Volumes }\end{array}$ & $\begin{array}{c}\text { Evaporator Pot } \\
\text { Volume }(\mathrm{mL})\end{array}$ & $\begin{array}{c}\text { Evaporator Feed } \\
\text { Volume }(\mathrm{mL})\end{array}$ & $\begin{array}{c}\text { End of Sequence } \\
\text { Sample }(\mathrm{mL})\end{array}$ \\
\hline $0-10$ & 325 & 325 & 10 \\
\hline $11-20$ & 315 & 315 & 25 \\
\hline $21-30$ & 290 & 290 & 10 \\
\hline $31-40$ & 280 & 280 & 25 \\
\hline $41-45$ & 255 & 255 & 10 \\
\hline $46-50$ & 245 & 245 & 10 \\
\hline $51-55$ & 235 & 235 & 25 \\
\hline
\end{tabular}

During the first day of Experiment \#2, the mist eliminator became filled with condensate sufficient to block the direct flow of vapors from the evaporator pot to the main condensers. Consequently, the mist eliminator behaved in 


\section{WSRC-TR-2002- 00411, Rev. 0 \\ SRT-RPP-2002-00206}

a manner similar to that of a second evaporator. As a result, acid was probably concentrated in the mist eliminator, and the small amounts of acid that did leave the mist eliminator were not condensed in the downstream condensers. Typical liquid volumes in the mist eliminator are on the order of 1-2 $\mathrm{mL}$ per process volume. In the case of Day 1 of Experiment \#2 (0-10 process volumes), $35-40 \mathrm{~mL}$ of condensate was in the mist eliminator after the first five process volumes, and the total acid in the pot was well below what was expected based solely on an analysis of the condensate.

All intermediate samples were analyzed for density using an Anton-Paar DMA 4500 density meter. The density meter is accurate to $0.0001 \mathrm{~g} / \mathrm{cm}^{3}$. Prior to analyzing samples, the instrument calibration is verified using deionized water. The samples are injected into the instrument, the instrument adjusts the sample temperature to $20^{\circ} \mathrm{C}$, and the sample is analyzed. Intermediate samples were also analyzed for cations content (ICPES and AA), anions (IC), free and total acid, total organic and inorganic carbon, heat capacity (using ASTM E1269-01), and thermal conductivity. ${ }^{7}$ The samples corresponding to 20 and 40 process volumes were also analyzed for viscosity, volatile organic compounds, and semi-volatile organic compounds.

Following precipitation in the evaporator pot, the solids were filtered at room temperature and analyzed using x-ray diffraction (XRD). The liquid was analyzed for density, viscosity, heat capacity, thermal conductivity, cations (ICPES and AA), anions, (IC), free and total acid, total organic and inorganic carbon, volatile organic compounds, and semi-volatile organic compounds. Based on the results from Experiment \#1, primary condensate samples were not analyzed for cations, anions, and carbon content. Secondary condensate samples were titrated for acid concentration.

\subsection{DISCUSSION OF RESULTS}

\subsection{EXPERIMENTAL DATA - EVAPORATOR CONCENTRATE}

The exact point of precipitation is difficult to determine because the solutions are heated to $55^{\circ} \mathrm{C}$ and then cooled to room temperature. Therefore they tend to become supersaturated before they will precipitate. Precipitation for Experiment \#1 was observed on the fourth day of the experiment, corresponding to the addition of 43-56 volumes of cesium eluate to the evaporator. Since the evaporator was held at a constant volume, this represents a concentration factor of 43-56. In Experiment \#2, a large amount of immediate precipitation was observed in the sample corresponding to 51-55 volumes of eluate. An examination of all sample bottles from Experiment \#2 after 20 days identified a trace amount of solids in both the 41-45 and 46-50 samples. Sodium nitrate was the only compound identified by $\mathrm{x}$-ray diffraction in a sample of the solids from the 51-55 sample.

Samples of the starting eluate and the final evaporator concentrate were analyzed from Experiment \#1. Table 4-1 contains the analytical results. The table also lists a concentration factor $(\mathrm{CF})$ which represents the Final Pot Sample concentration divided by the TFL Feed AZ-102 concentration. The CF values for $\mathrm{Cr}, \mathrm{Cu}, \mathrm{Fe}, \mathrm{K}$, and $\mathrm{S}$ clearly indicate that the overall experiment concentration factor is on the order of 56. The CF value of 42.1 for $\mathrm{Na}$ is expected because sodium nitrate $\left(\mathrm{NaNO}_{3}\right)$ is the identified precipitate. The $\mathrm{CF}$ value for Cs of 3.8 implies that $\mathrm{CsNO}_{3}$ may be a co-precipitate with $\mathrm{NaNO}_{3}$, but at levels too low to be detected by XRD. It should be noted that values of $16.0 \mathrm{mg} / \mathrm{L} \mathrm{Cs}$ and $3.70 \mathrm{mg} / \mathrm{L} \mathrm{Al}$ are used for the TFL AZ-102 Feed concentration based on the data in Table 4-3.

A comparison of the sulfur value ( $\mathrm{S}$ by ICPES) with that of sulfate $\left(\mathrm{SO}_{4}\right.$ by IC) shows good agreement. A value of $13.4 \mathrm{mg} / \mathrm{L}$ of S corresponds to a $\mathrm{SO}_{4}$ concentration of $40.2 \mathrm{mg} / \mathrm{L}$. The comparison suggests that the initial sulfate value of $33 \mathrm{mg} / \mathrm{L}$ by IC may be a little low, thereby causing the CF value (69.1) to be a little high. As is discussed later, the average feed value from Table 4-3 is used for calculations in Table 4-1. The difference in TOC and TIC values relative to a CF of 56 is addressed in Section 4.4. The CF values for nitrate, total acid, and free acid are not addressed because it is understood that much of the nitrate is collected in the condensate. Data for total acid, free acid, and density are also recorded in Table 4-1.

${ }^{6}$ E1269-01 - Standard Test Method for Determining Specific Heat Capacity by Differential Scanning Calorimetry. ASTM International (West Conshohocken, PA), Copyright 2002.

${ }^{7}$ Garti, Nissim. Thermal Behavior of Dispersed Systems. Marcel Dekker, Inc. (New York, 2001), pp. 187-194. 
Table 4-1. Experiment \#1 Evaporator Concentrate Data

\begin{tabular}{|c|c|c|c|c|c|c|c|}
\hline $\begin{array}{c}\text { Analyte } \\
(\mathrm{mg} / \mathrm{L})\end{array}$ & $\begin{array}{c}\text { TFL Feed } \\
\text { AZ-102 }\end{array}$ & $\begin{array}{l}\text { Final Pot } \\
\text { Sample }\end{array}$ & CF & $\begin{array}{c}\text { Analyte } \\
(\mathrm{mg} / \mathrm{L})\end{array}$ & $\begin{array}{c}\text { TFL Feed } \\
\text { AZ-102 }\end{array}$ & $\begin{array}{l}\text { Final Pot } \\
\text { Sample }\end{array}$ & CF \\
\hline $\mathrm{Na}$ & 1520 & 64000 & 42.1 & S (ICPES) & 13.4 & 784 & 58.5 \\
\hline $\mathrm{Al}^{*}$ & 3.70 & 173 & 46.8 & & & & \\
\hline $\mathrm{Ca}^{*}$ & 6.5 & 578 & 88.9 & NO3 & 34000 & 512000 & \\
\hline $\mathrm{Cr}$ & 59.3 & 3150 & 53.1 & $\mathrm{~F}$ & $<20$ & 151 & \\
\hline $\mathrm{Cu}$ & 2.88 & 148 & 51.4 & $\mathrm{Cl}$ & $<20$ & 33 & \\
\hline $\mathrm{Fe}$ & 5.18 & 289 & 55.8 & $\mathrm{SO}^{*}$ & 37.5 & 2280 & 60.8 \\
\hline $\mathrm{K}$ & 25.8 & 1420 & 55.0 & $\mathrm{PO} 4$ & $<100$ & 68 & \\
\hline $\mathrm{Cs}^{*}$ & 16.0 & 60.5 & 3.8 & $\mathrm{C} 2 \mathrm{O} 4$ & $<100$ & 222 & \\
\hline Total Acid (M) & 0.52 & 4.86 & & $\mathrm{CHO} 2$ & $<100$ & $<100$ & \\
\hline Free Acid (M) & 0.52 & na & & TOC & 52.8 & 1550 & 29.4 \\
\hline Density (g/cc) & 1.0198 & 1.3508 & & TIC & 11.5 & 60.2 & 5.2 \\
\hline
\end{tabular}

* Indicates TFL AZ-102 Feed value that has been updated based on intermediate sample data in Table 4-3

Table 4-2. Experiment \#2 Evaporator Concentrate Data

\begin{tabular}{|c|c|c|c|c|c|c|c|}
\hline $\begin{array}{c}\text { Analyte } \\
\text { (mg/L) }\end{array}$ & $\begin{array}{c}\text { TFL Feed } \\
\text { AZ-102 }\end{array}$ & $\begin{array}{l}\text { Final Pot } \\
\text { Sample }\end{array}$ & CF & $\begin{array}{c}\text { Analyte } \\
(\mathrm{mg} / \mathrm{L})\end{array}$ & $\begin{array}{c}\text { TFL Feed } \\
\text { AZ-102 }\end{array}$ & $\begin{array}{l}\text { Final Pot } \\
\text { Sample }\end{array}$ & CF \\
\hline $\mathrm{Na}$ & 1520 & 65400 & 43.0 & $S$ (ICPES) & 13.4 & na & \\
\hline $\mathrm{Al}$ & 3.7 & 191 & 51.6 & & & & \\
\hline $\mathrm{Ca}$ & 6.5 & 367 & 56.5 & NO3 & 34000 & 471000 & \\
\hline $\mathrm{Cr}$ & 59.3 & 3500 & 59.0 & $F$ & $<20$ & 79 & \\
\hline $\mathrm{Cu}$ & 2.88 & 170 & 59.0 & $\mathrm{Cl}$ & $<20$ & $<20$ & \\
\hline $\mathrm{Fe}$ & 5.18 & 324 & 62.5 & SO4 & 37.5 & 2320 & 61.9 \\
\hline $\mathrm{K}$ & 25.8 & 1450 & 56.2 & $\mathrm{PO} 4$ & $<100$ & $<100$ & \\
\hline Cs & 16 & 886 & 55.4 & $\mathrm{C} 2 \mathrm{O} 4$ & $<100$ & 201 & \\
\hline Total Acid (M) & 0.52 & 4.81 & & $\mathrm{CHO} 2$ & $<100$ & $<100$ & \\
\hline Free Acid (M) & 0.52 & 4.12 & & & & & \\
\hline \multirow[t]{2}{*}{ Density (g/cc) } & 1.0198 & 1.3153 & & TOC & 52.8 & 2420 & 46.8 \\
\hline & & & & TIC & 11.5 & 222 & 19.3 \\
\hline
\end{tabular}

Samples of the starting eluate and the final evaporator concentrate were analyzed from Experiment \#2. Table 4-2 contains the analytical results. The table also lists a concentration factor (CF) which represents the Final Pot Sample concentration divided by the TFL Feed AZ-102 concentration. The $\mathrm{CF}$ values for $\mathrm{Al}, \mathrm{Ca}, \mathrm{Cr}, \mathrm{Cs}, \mathrm{Cu}, \mathrm{Fe}, \mathrm{K}$, and $\mathrm{SO} 4$ indicate that the overall experiment concentration factor is on the order of 55 . The $\mathrm{CF}$ value of 43.0 for $\mathrm{Na}$ is expected because sodium nitrate $\left(\mathrm{NaNO}_{3}\right)$ is the identified precipitate. The $\mathrm{CF}$ value for $\mathrm{Cs}$ of 55.4 is very interesting because in Experiment \#1 the CF value for Cs was 3.8. It is unclear whether the Cs data for Experiment \#1 is low because of analytical error or because of Cs co-precipitation. The CF values for nitrate, total acid, and free acid are not addressed because it is understood that much of the nitrate is collected in the condensate. Data for total acid, free acid, and density are also recorded in Table 4-2.

Intermediate samples of the evaporator concentrate were also analyzed from Experiment \#2. The intermediate sample data are listed in Table 4-3. The intermediate concentration data exhibit a linear increase consistent with the volume of cesium eluate evaporated in the system. This is also evident in the color of the eluate concentrate. Because of the high concentration of chromium, a visible purple tint is imparted to the solution (Figure 4-1). 
Figure 4-1. Increasing Cr Concentration in Evaporator Concentrate

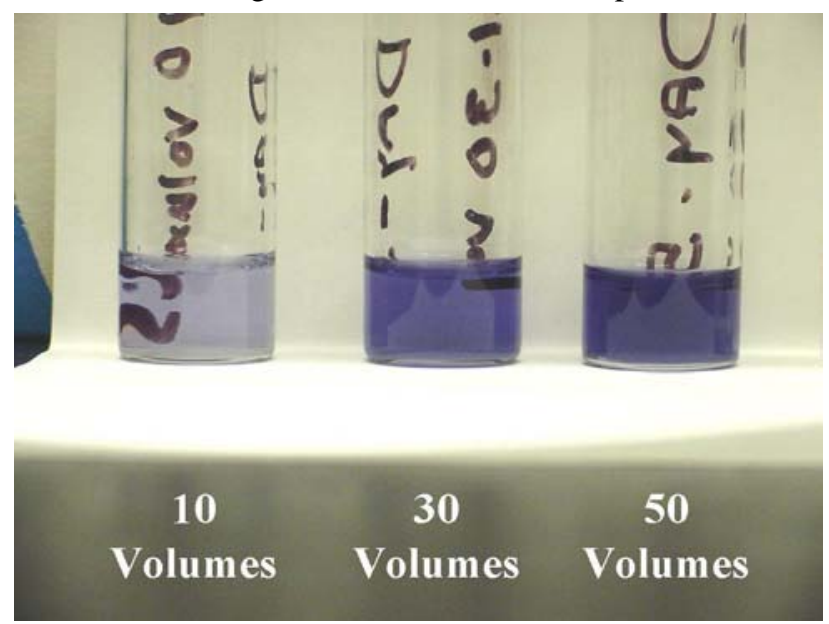

The right-most column of Table 4-3 uses all of the intermediate sample data in conjunction with the appropriate concentration factors to calculate the TFL AZ-102 cesium eluate concentrations. These average feed values show very good agreement with all of the feed values initially measured with the exception of cesium. Because the calculated average values are viewed to be more reliable, they are used for Al, Ca, Cs and SO4 in Table 4-1 and Table 4-2.

Table 4-3 also contains a calculation of the CF for sodium, chromium, cesium and potassium - the four most dominant cations. Consistent with what is expected, the $\mathrm{CF}$ values at 10,20 , and 30 process volumes correlate very well with the total volumes fed. The values at 40 process volumes are a little high while the values at 50 process volumes are a little low. However, because the CF values for all four cations are almost the same, the low values at 50 process volumes are probably due to experimental uncertainty, and not precipitation. The CF values in Table 4-1 and Table 4-2 further confirm this conclusion because both tables show that only sodium has a low CF value after precipitation.

The change in CF values for TIC/TOC being less that 56 indicate that some TOC and TIC components are lost to both the condensate and the offgas system. A review of the total organic carbon (TOC) and total inorganic carbon (TIC) data reveals a significant build-up of organic carbon in the concentrate (Table 4-1 and Table 4-2) while most of the inorganic carbon passes to the condensate (Table 4-7). Of the measured TOC, approximately $70 \%$ are retained in the concentrate; only $11 \%$ of the measured TIC are retained in the concentrate.

Since the pot volume is 0.25 liters, a material balance can be conducted. The total TIC fed to the system is $161 \mathrm{mg}$ ( 56 volumes $\times 11.5 \mathrm{mg} / \mathrm{L}$ per volume $\times 0.25$ liters). The total TIC is the condensate and final evaporator concentrate is $157.8 \mathrm{mg}-98.0 \%$ recovery. The total TOC fed to the evaporator is $739 \mathrm{mg}$ (56 volumes $\mathrm{x} 52.8 \mathrm{mg} / \mathrm{L}$ per volume $\mathrm{x} 0.25$ liters). The total TOC in the condensate and final evaporator concentrate is $603 \mathrm{mg}-81.6 \%$ recovery. The difference can be analytical error. However, it is also probable that a portion of the TOC loss can be attributed to either the formation of an undetectable amount of sodium oxalate precipitate, ${ }^{8}$ or to the degradation of TOC components to form carbon dioxide and water. ${ }^{9}$ The presence of TOC and TIC in the concentrate from Experiment \#2 is somewhat above that of Experiment \#1, but it is unclear how the operating anomaly from 1-10 process volumes affects that TOC and TIC concentrations. Because TOC/TIC were not measured for Experiment \#2, material balances cannot be calculated.

Attempts to identify the organic and inorganic compounds were inconclusive. Approximately $15 \%$ of the TOC can be accounted for as oxalate (Table 4-1). Analyses of the concentrate from samples at 20, 40 and 55 process volumes

\footnotetext{
${ }^{8}$ R. A. Pierce and T. B. Edwards. "Cesium Eluate Evaporation Solubility and Physical Property Behavior," WSRCTR-2002-00273, dated June 11, 2002.

${ }^{9}$ R. A. Pierce. "Cesium Eluate Analytical Data Evaluation,” WSRC-TR-2001-00594, dated January 2002.
} 


\section{WSRC-TR-2002- 00411, Rev. 0 SRT-RPP-2002-00206}

showed no detectable volatile or semi-volatile organic compounds (detection limit is $0.1 \mathrm{mg} / \mathrm{L}$ ). This is not surprising because volatiles and semi-volatiles are not expected in a solution evaporated under vacuum. Therefore, the remaining organic components in the concentrate are non-volatile. The identity of the inorganic carbon is also unclear. Although the first assumption is that the TIC is carbonate, carbonate is not stable in strong acid.

Table 4-3. Experiment \#2 Evaporator Intermediate Concentrate Data

\begin{tabular}{|c|c|c|c|c|c|c|c|c|}
\hline \multicolumn{9}{|c|}{ EXPERIMENT \#2 INTERMEDIATE CONCENTRATE (in mg/L) } \\
\hline \multirow[b]{2}{*}{ Analyte } & \multirow{2}{*}{$\begin{array}{c}\text { TFL Feed } \\
\text { AZ-102 }\end{array}$} & \multicolumn{6}{|c|}{ Process Volumes Fed to the Evaporator } & \multirow{2}{*}{$\begin{array}{c}\text { Average } \\
\text { Feed }\end{array}$} \\
\hline & & 0 & 10 & 20 & 30 & 40 & 50 & \\
\hline $\mathrm{Na}$ & 1520 & & 14100 & 30900 & 45400 & 63100 & 70700 & 1494.7 \\
\hline $\mathrm{Al}$ & 4.47 & & 47.8 & 78.2 & 115.3 & 148.3 & 163.4 & 3.7 \\
\hline $\mathrm{Ca}$ & 5.43 & & 58 & 135 & 197 & 274 & 304 & 6.5 \\
\hline $\mathrm{Cr}$ & 59.3 & & 571 & 1200 & 1800 & 2520 & 2750 & 58.9 \\
\hline $\mathrm{Cu}$ & 2.88 & & 30.7 & 61.9 & 87 & 124 & 135 & 2.9 \\
\hline $\mathrm{Fe}$ & 5.18 & & 50 & 106 & 164 & 231 & 250 & 5.3 \\
\hline $\mathrm{K}$ & 25.8 & & 219 & 520 & 760 & 1070 & 1210 & 25.2 \\
\hline Cs & 7.41 & & 157 & 321 & 458 & 685 & 779 & 16.0 \\
\hline CF for $\mathrm{Na}$ & & & 9.4 & 20.7 & 30.4 & 42.2 & 47.3 & \\
\hline CF for $\mathrm{Cr}$ & & & 9.6 & 20.2 & 30.4 & 42.5 & 46.4 & \\
\hline CF for $\mathrm{K}$ & & & 8.5 & 20.2 & 29.5 & 41.5 & 46.9 & \\
\hline $\mathrm{CF}$ for $\mathrm{Cs}$ & & & 9.8 & 20.1 & 28.6 & 42.8 & 48.7 & \\
\hline Total Acid (M) & 0.52 & 7.25 & 4.47 & 6.18 & 5.21 & 5.44 & 4.66 & \\
\hline Free Acid (M) & 0.52 & 7.25 & 4.47 & 6.18 & 4.73 & 4.46 & 4.16 & \\
\hline Density (g/cc) & 1.0198 & 1.2287 & 1.1732 & 1.2625 & 1.2730 & 1.3155 & 1.3372 & \\
\hline NO3 & 34000 & & 288000 & 484000 & 415000 & 538000 & 489000 & \\
\hline $\mathrm{F}$ & $<20$ & & $<200$ & $<200$ & $<200$ & $<200$ & $<200$ & \\
\hline $\mathrm{Cl}$ & $<20$ & & $<200$ & $<200$ & $<200$ & $<200$ & $<200$ & \\
\hline SO4 & 33 & & 340 & 800 & 1060 & 1620 & 1800 & 37.5 \\
\hline $\mathrm{PO} 4$ & $<100$ & & $<1000$ & $<1000$ & $<1000$ & $<1000$ & $<1000$ & \\
\hline $\mathrm{C} 2 \mathrm{O} 4$ & $<100$ & & $<1000$ & $<1000$ & $<1000$ & $<1000$ & $<1000$ & \\
\hline $\mathrm{CHO} 2$ & $<100$ & & $<1000$ & $<1000$ & $<1000$ & $<1000$ & $<1000$ & \\
\hline TOC & 52.8 & & & 91.6 & & 166 & & \\
\hline TIC & 11.5 & & & 194 & & 195 & & \\
\hline & & \multicolumn{6}{|c|}{ Process Volumes Fed to the Evaporator } & \\
\hline & & 5 & 15 & 25 & 35 & 45 & 55 & \\
\hline Total Acid (M) & & & & & 4.49 & 5.16 & & \\
\hline Density (g/cc) & & 1.1290 & 1.2174 & 1.2828 & 1.2886 & 1.3228 & 1.3519 & \\
\hline
\end{tabular}

\subsection{SOLUBILITY - EVAPORATOR CONCENTRATE}

\subsubsection{Experiment vs. OLI Model}

The performance of the OLI model corresponds well with the observed behavior of the two experiments. The model predicted the formation of NaNO3 solids at saturation - this was observed in both tests. The OLI model predicted saturation at a volume reduction factor of 50 - meaning 50 pot volumes added to the evaporator while maintaining a constant evaporator volume. In Experiment \#1, solids formed between 42 and 56 volumes. In Experiment \#2, large 


\section{WSRC-TR-2002- 00411, Rev. 0 \\ SRT-RPP-2002-00206}

amounts of solid were observed immediately upon cooling of the solution containing a volume reduction of 51-55. After several days a small amount of solid was found in the samples at 41-45 volumes and 46-50 volumes.

In the earlier studies on cesium eluate saturation, an attempt to correspond solubility parameters to total acid plus salt was discussed. ${ }^{4}$ Following that approach, the data from Experiment \#2 is plotted in Figure 4-2 along with the prediction from the OLI model. Also included is the solubility behavior observed for AZ-102 during earlier work. The OLI model shows excellent agreement with the earlier solubility work. The saturation point for OLI is almost directly on the solubility curve.

The fluctuating behavior in the actual experiment shown in Figure 4-2 raises questions. A review of the intermediate sample data shows that the only major fluctuating measurement is total acid. The range of fluctuation is such that correlating the intermediate samples from the experiment with OLI predictions becomes difficult because the conditions for comparison are not identical. As a result, based on experimental data, Figure 4-2 shows precipitation occurring at 41-45 volumes, which it did. The same figure shows that the OLI model prediction also agrees with earlier solubility data. It is unclear if the fluctuations in total acid are a phenomenon that is solely a function of the experimental technique - hence this effect will not be observed in pilot-scale or full-scale operation. While experimental technique is the more likely explanation, it is still possible that the acid variability is a chemical behavior issue.

A material balance around acid was conducted for both tests. Total acid in the system at the start Experiment \#1 is 1.81 moles $(7.25 \mathrm{M} \times 0.25 \mathrm{~L})$. The total amount of acid added with the eluate is 7.28 moles $(0.52 \mathrm{M} \times 56$ volumes $\mathrm{x}$ $0.25 \mathrm{~L} /$ volume $)$. The total acid evaporated is 8.39 moles $(0.599 \mathrm{M} \times 56$ volumes $\times 0.25 \mathrm{~L} /$ volume $)$. The total acid in the pot at the end of the test is 1.22 moles ( $4.86 \mathrm{M}$ x 0.25 liters). A material balance shows 9.09 moles of acid added to the system and a total of 9.61 moles measured in the condensate and final pot solution, a $95 \%$ material balance.

Calculating a material balance for Experiment \#2 is more easily performed using concentration data instead of total moles because of the frequent removal of samples. Total acid in the system at the start Experiment \#2 is 7.25 M. Total acidity added with the eluate is the equivalent of $28.60 \mathrm{M}(0.52 \mathrm{M}$ x 55 volumes $)$. The total acid evaporated from Experiment $\# 2$ is the equivalent of $25.74 \mathrm{M}(0.486 \mathrm{M}$ x 55 volumes). Final pot acidity was $4.81 \mathrm{M}$. The data produces an estimated material balance of $85 \%$. The acid losses could be caused by the process upset that occurred during the first day of the experiment.

The variability in total acid data does not appear to be caused by operator error while performing the analytical technique. Measurements of total acid by autotitriation and titration by hand yield similar results. It raises questions regarding the accuracy of total acid analyses in the presence of large amounts of nitrate salts. Nitrate salts can form complexes with acid that impact titration. 
Figure 4-2. OLI Model Prediction vs. Experimental Data

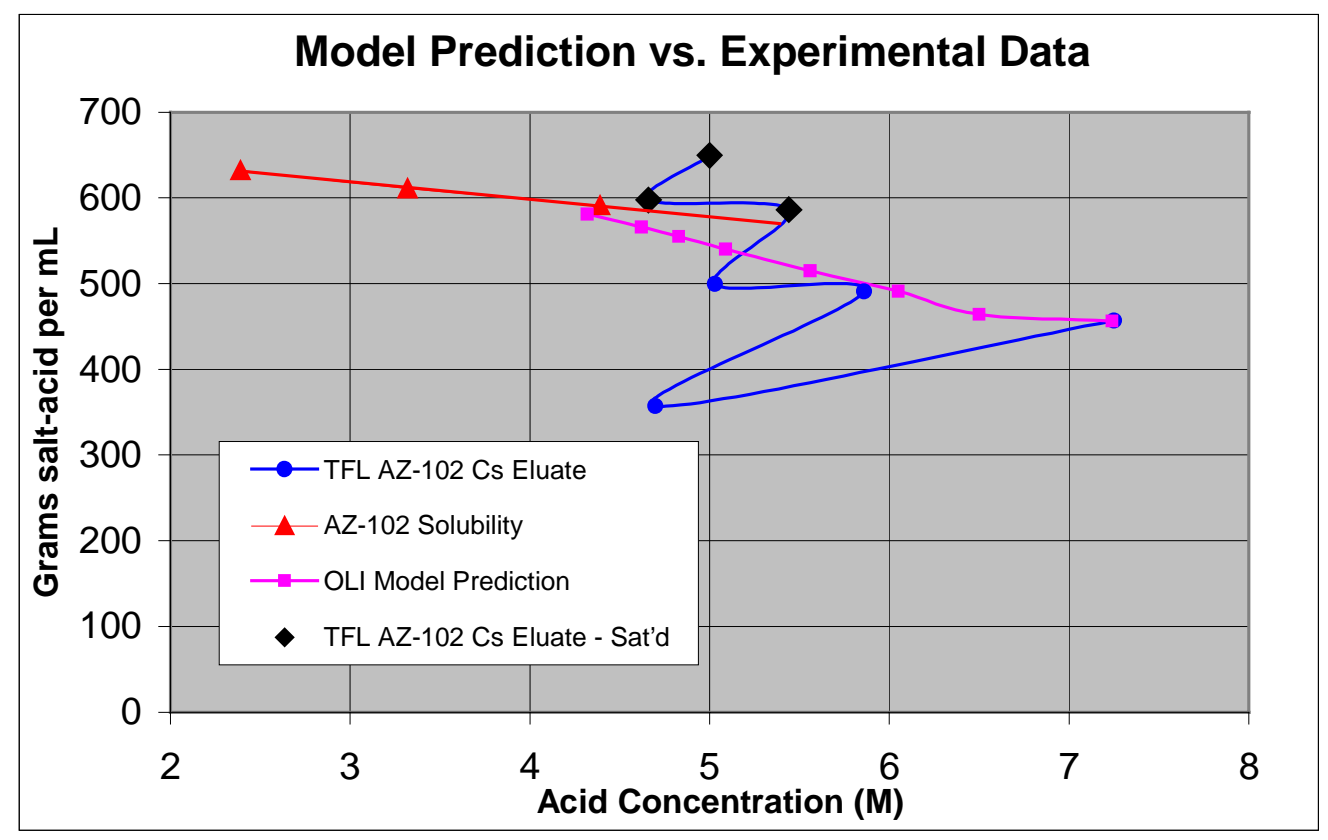

\subsubsection{Experiment vs. Solubility Report Data}

The experimental data was also compared with predictions from the earlier cesium eluate solubility report. The first comparison was based on the parameter estimates developed from the body of data. Parameter estimates for each of the seven major variables can be multiplied with the cation mole percent values to obtain an estimated solubility. The calculation to estimate solubility is performed in the following manner:

Estimated Solubility $=\Sigma(\text { cation solubility parameter estimate })_{\mathrm{i}}(\text { cation mole percent })_{\mathrm{i}}$

The solubility parameter estimates are listed in Table 4-4. ${ }^{10}$ The output from the calculation is an estimate of the total acid plus salt concentration that will produce precipitation. Performing the calculations using a concentration factor of 45 with the data in Table 3-1 and the measured total acid value in Table 4-3 produces a predicted acid plus salt concentration of $584 \mathrm{~g} / \mathrm{L}$ at solubility. Experimental data yields an acid plus salt concentration of $599 \mathrm{~g} / \mathrm{L}$ when 45 volumes have been fed to the evaporator pot.

Table 4-4. Solubility Parameter Estimates for $20-22^{\circ} \mathrm{C}$ Data MOLE \% PARAMETER ESTIMATES

\begin{tabular}{|c|c|c|c|c|c|c|c|}
\hline $\mathrm{Al}$ & $\mathrm{Ca}$ & $\mathrm{Cs}$ & $\mathrm{Fe}$ & $\mathrm{H}$ & $\mathrm{K}$ & $\mathrm{Na}$ & Others \\
\hline 0.00657 & 0.01215 & 0.01655 & 0.01046 & 0.00580 & 0.00957 & 0.00586 & 0.00454 \\
\hline
\end{tabular}

A second comparison of the experimental data with earlier results involves plotting the experimental data against sodium nitrate solubility as a function of nitric acid concentration. This approach can be used for the TFL AZ-102 simulant because, as shown in Table 3-1, sodium nitrate makes up 93 percent by weight of the total non-acid cations. The experimental data plots total sodium nitrate concentration as a function of measured total acid (Figure 4-3). When plotted against sodium nitrate solubility, good agreement between the TFL AZ-102 simulant evaporation and earlier solubility data is observed. The large black diamonds on the graph indicate samples that produced precipitation.

${ }^{10}$ R. A. Pierce and T. B. Edwards. "Cesium Eluate Evaporation Solubility and Physical Property Behavior," WSRC-TR-2002-00273, dated June 11, 2002. 
Figure 4-3. Experimental Data Compared to Sodium Nitrate Solubility

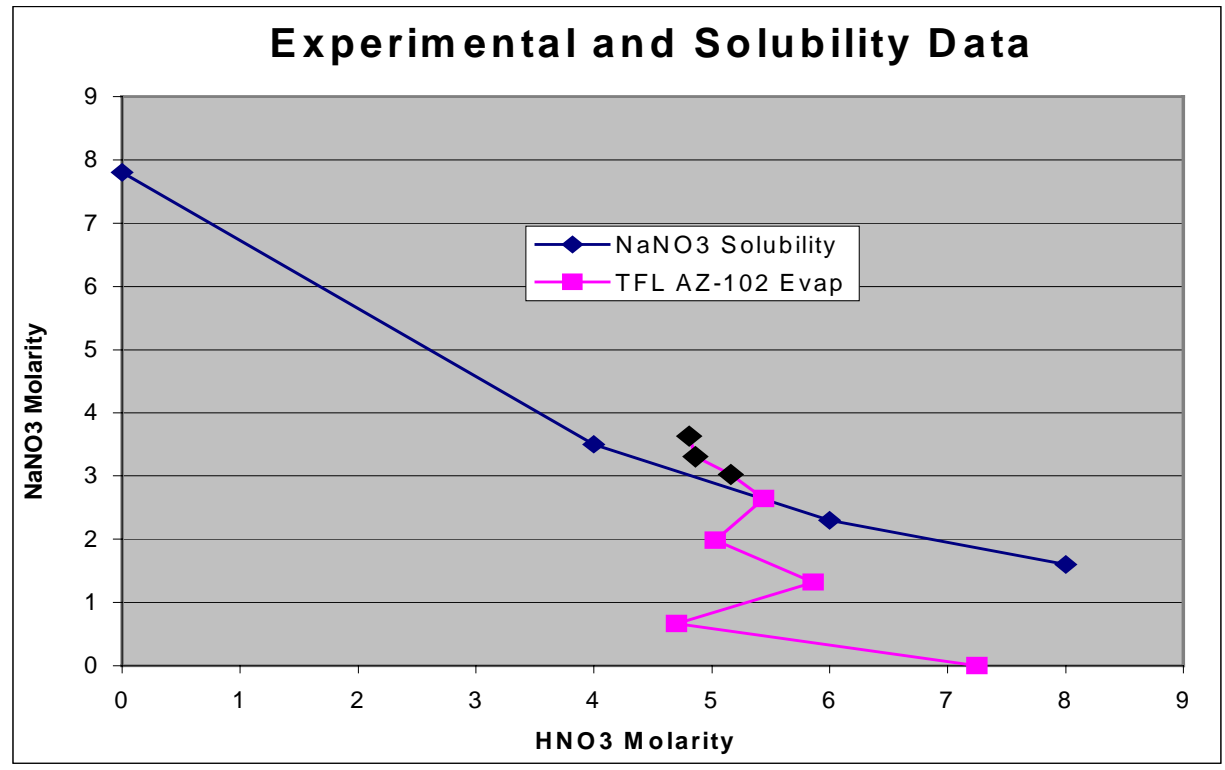

\subsection{PHYSICAL PROPERTIES - EVAPORATOR CONCENTRATE}

In addition to solubility and density data, physical property predictions were also made using the OLI model. The predictions are compared to the experimental data throughout this section as well as to earlier data. A summary table of the predicted and measured data is included as Table 4-5. The table contains density, viscosity, heat capacity, and thermal conductivity data. Boiling point data will be presented in a separate table.

Table 4-5. Summary of predicted and Measured Physical Property Data

\begin{tabular}{|c|c|c|c|c|c|c|c|}
\hline $\begin{array}{c}\text { Process } \\
\text { Volumes }\end{array}$ & \multicolumn{2}{|c|}{$\begin{array}{c}\text { Density } \\
(\mathrm{g} / \mathrm{cc})\end{array}$} & \multicolumn{2}{c|}{$\begin{array}{c}\text { Viscosity (cP) } \\
\text { @ } 50^{\circ} \mathrm{C}\end{array}$} & \multicolumn{2}{c|}{$\begin{array}{c}\text { Heat Capacity } \\
(\mathrm{cal} / \mathrm{g}-\mathrm{C}) @ 50^{\circ} \mathrm{C}\end{array}$} & $\begin{array}{c}\text { Thermal Conductivity } \\
(\mathrm{W} / \mathrm{m}-\mathrm{C}) @ 50^{\circ} \mathrm{C}\end{array}$ \\
\hline & OLI & Test & OLI & Test & OLI & Test & Test \\
\hline 10 & 1.244 & 1.173 & 1.223 & & 0.756 & 0.872 & 0.690 \\
\hline 20 & 1.266 & 1.263 & 1.308 & 0.947 & 0.744 & 0.840 & 0.669 \\
\hline 30 & 1.288 & 1.273 & 1.395 & & 0.736 & 0.838 & 0.588 \\
\hline 40 & 1.310 & 1.316 & 1.454 & 1.167 & 0.728 & 0.798 & 0.615 \\
\hline 50 & 1.332 & 1.337 & 1.448 & & 0.717 & 0.801 & 0.709 \\
\hline
\end{tabular}

\subsubsection{Density}

A plot of the density in Table 4-3 as a function of process volumes fed is plotted in Figure 4-4. The red square on Figure 4-4 represents the density after precipitation has occurred. The data show a linear increase through the first 20 volumes, an unexpected decrease to a local minimum, and then a linear increase from 30-55 volumes. Of particular interest is the slope of the line before and after the local minimum at 30 volumes. The slope before the minimum is three times the slope following the minimum. The increase slope is caused by the problem with the mist eliminator experienced during the first five evaporator volumes. If the assumption of normal evaporator behavior is made, a straight line (dashed line) can be drawn from the theoretical density of the starting acid (0 volumes) to the density at 25 volumes. The slopes before and after the local minimum are comparable. Nonetheless, the measured density would still pass through a distinct minimum. The behavior is further discussed in Section 4.3.1.1. 
Figure 4-4. TFL AZ-102 Cesium Eluate Evaporation Density

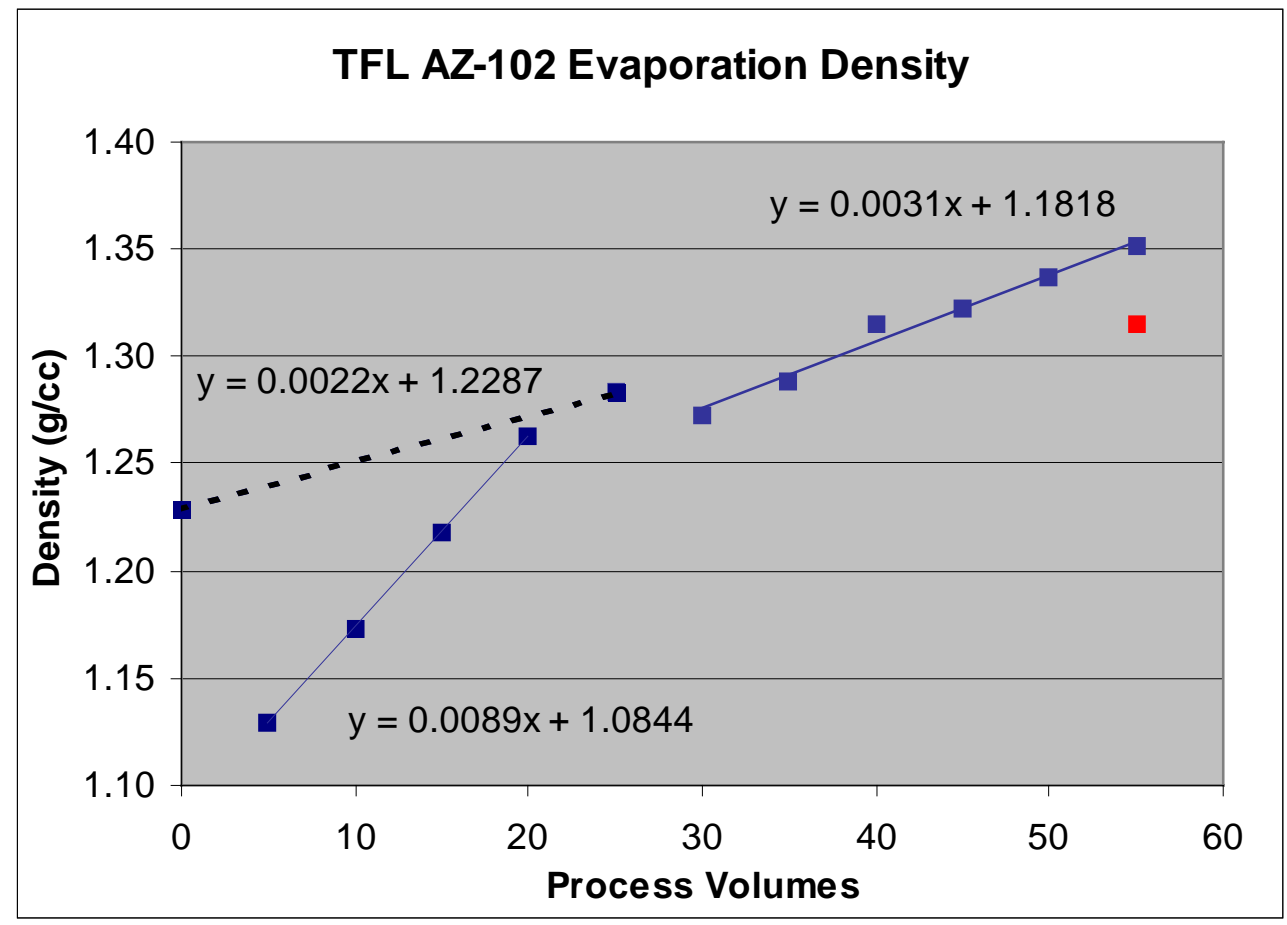

\subsubsection{Role of Free Acid}

One explanation for the shift in slope and the local minimum observed in Figure 4-4 might be attributable to cationic binding of free acid. A change in the way that free acid is bound may also reflect the way cations bind to each other and form ionic complexes. Changes in binding characteristics will affect overall density. Figure 4-5 compares the measured pot density data with the measured free acid and total acid data in Table 4-3. The figure shows that free acid are identical through the first 20 process volumes. At 30 process volumes the free acid becomes less than the total acid. At the same time, density passes through a relative minimum at 25-30 process volumes. The specific reasons for the drop in free acid are unknown. An explanation of the low acid value observed in Figure 4-5 at ten process volumes is discussed in Section 4.3.1.2.

\subsubsection{Experiment vs. OLI Model:}

A comparison of the density values predicted by the OLI model with the data from Experiment \#2 shows good agreement (Figure 4-6). The only data points with significant variance are those from the early portion of the test when experimental error caused the acid to be low. During the first day of Experiment \#2, the mist eliminator became filled with condensate sufficient to block the flow of vapors directly from the evaporator pot to the main condensers. Consequently, the mist eliminator behaved in a manner similar to that of a second evaporator. As a result, acid was probably concentrated in the mist eliminator, and the small amounts of acid that did leave the mist eliminator were not condensed.

The standard procedure for the test is to return any condensate from the mist eliminator into the evaporator pot. It should also be noted, however, that process samples are collected before the mist eliminator condensate is returned to the pot. Typical liquid volumes in the mist eliminator are on the order of 1-2 $\mathrm{mL}$ per process volume.

Consequently, the total acid in the pot may be biased low. In the case of Day 1 of Experiment \#2 (0-10 process volumes), $35-40 \mathrm{~mL}$ of condensate was in the mist eliminator after the first five process volumes, and the total acid in the pot was well below what was expected based on an analysis of the condensate. However, it should be noted that the measured density 1.13 correlates well with a theoretical density for $4.47 \mathrm{M} \mathrm{HNO}_{3}$ of 1.14 . 
Figure 4-5. TFL Cesium Eluate Density and Free Acid

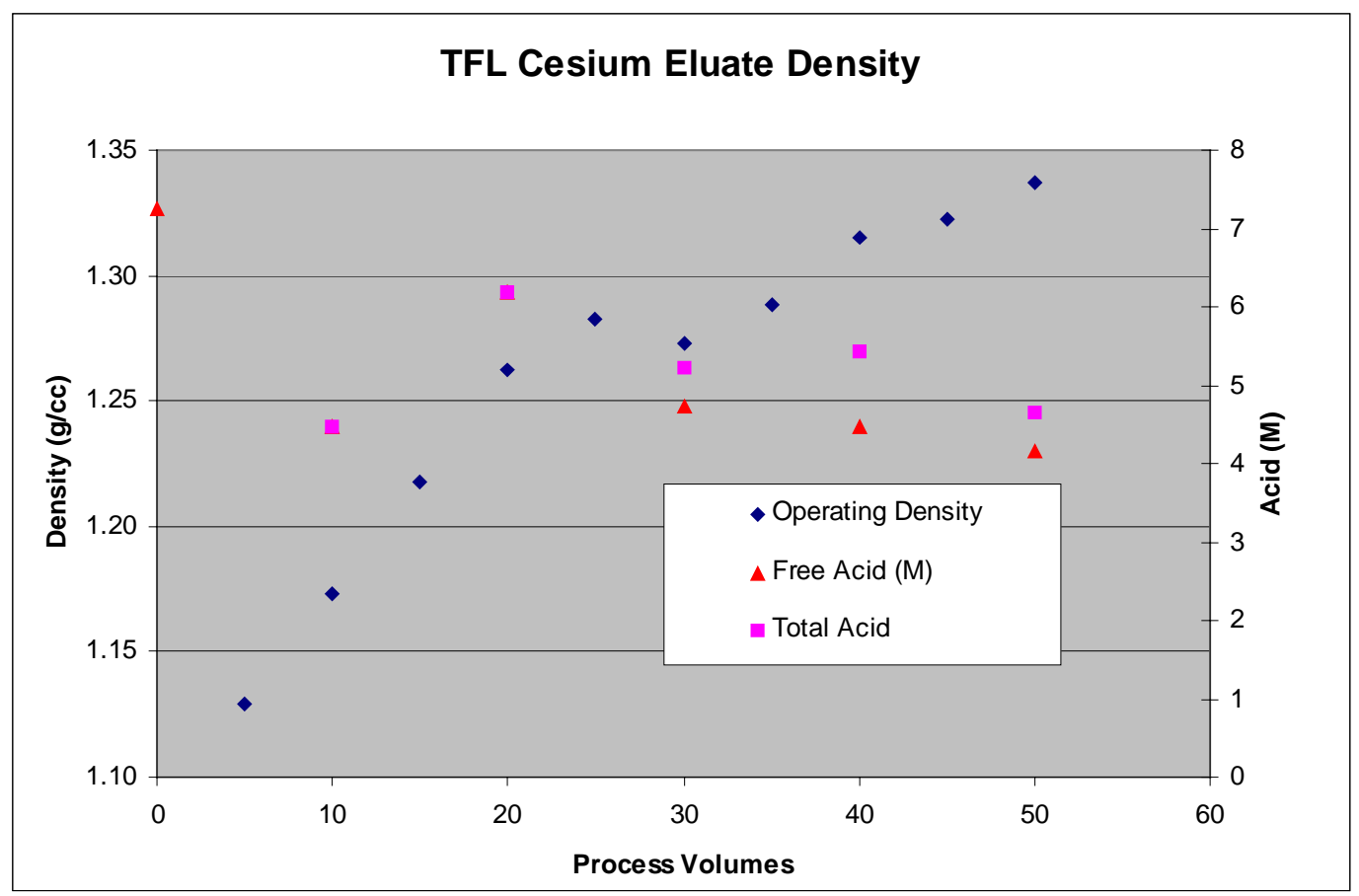

4.3.1.3 Experimental Density vs. Solubility Report Data

A comparison of the experimental data with data from the earlier solubility report exhibits good agreement (Figure 4-7). The data from the experiment is plotted (red circles) with all of the densities measured for the solubility report (in gray). The graph shows that the measured data for the experiment are consistent with those observed throughout solubility testing.

Figure 4-6. OLI Model Density Prediction vs. Experimental Data

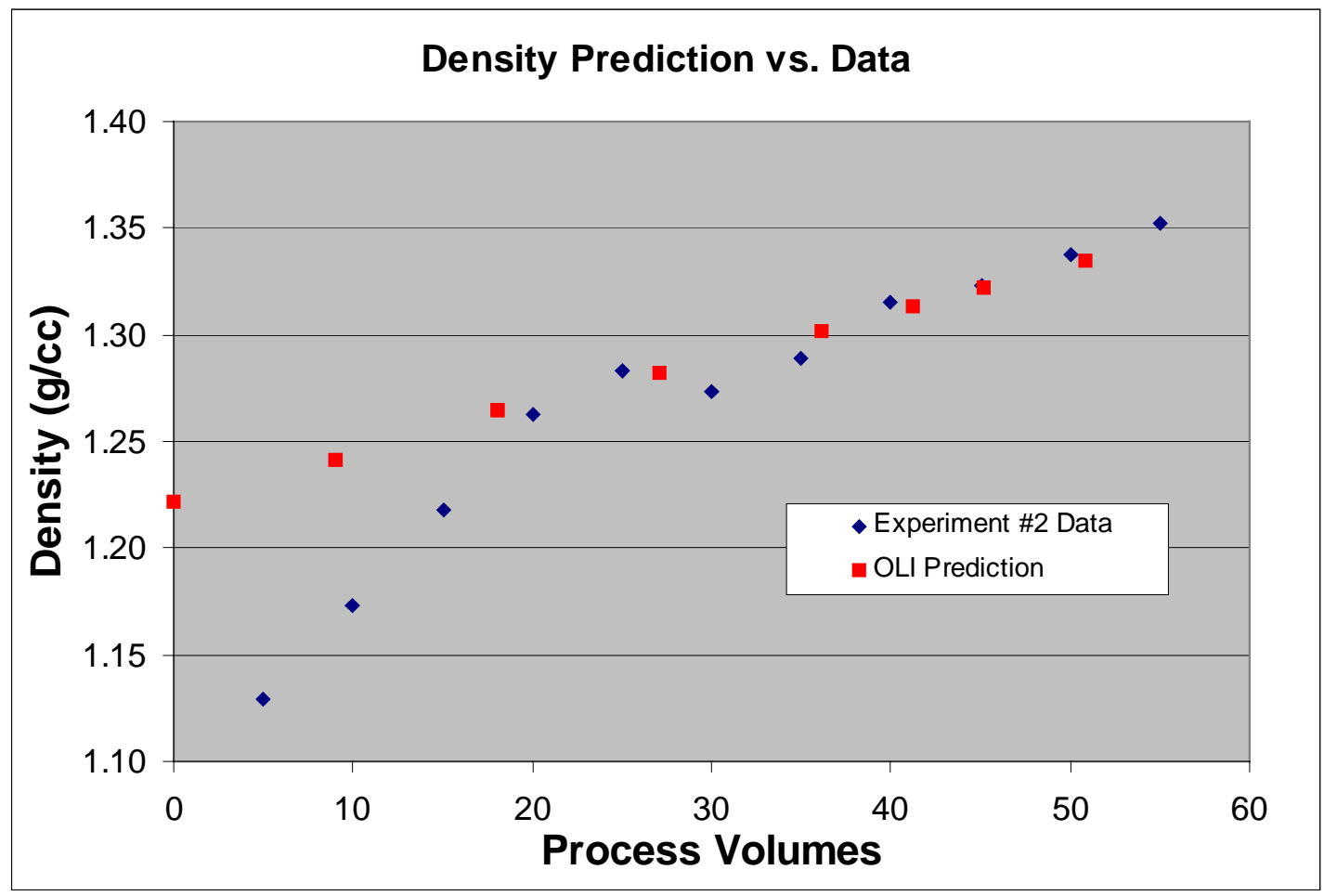


Figure 4-7. Experimental Density Data and Density Data Matrix

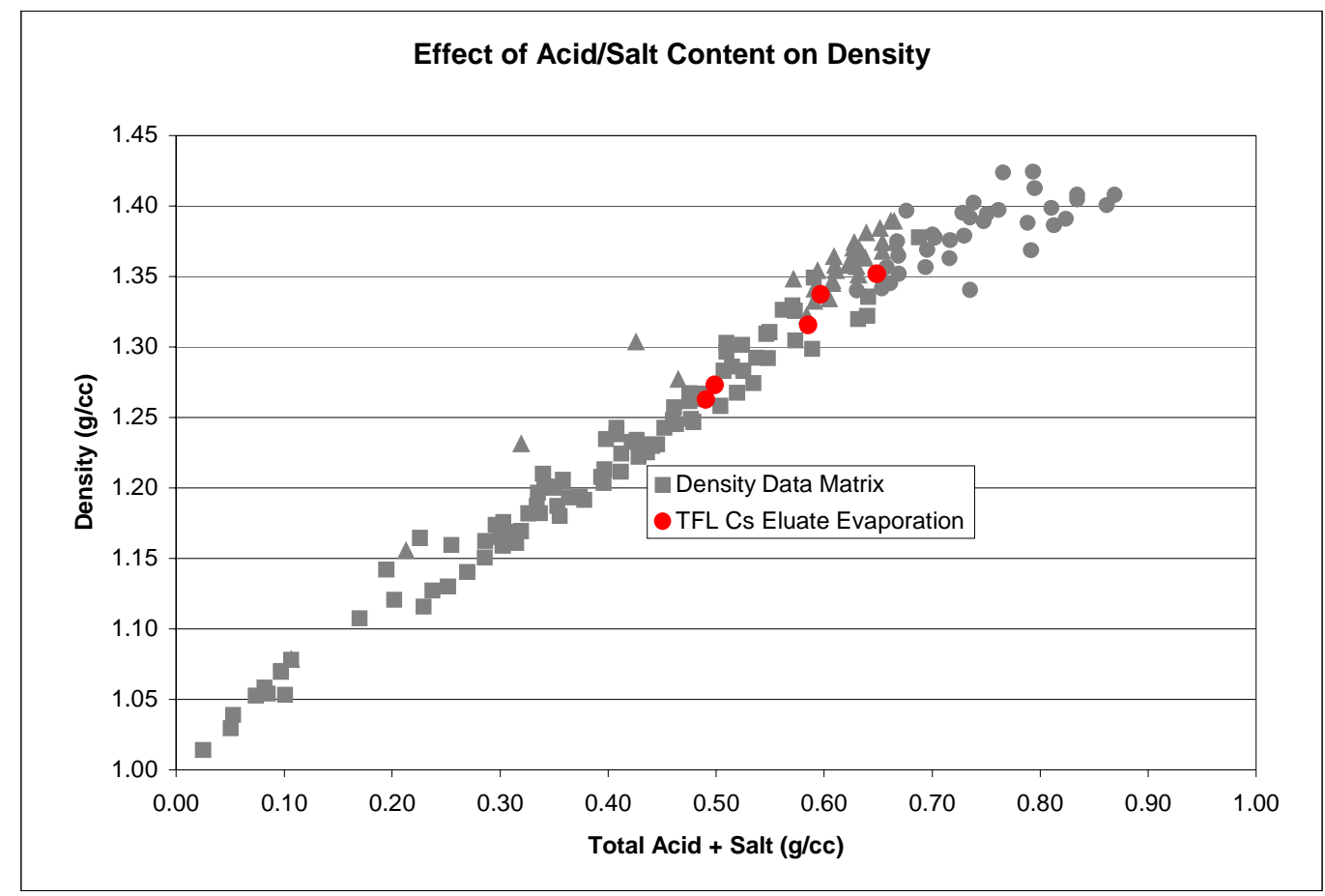

\subsubsection{Viscosity}

Viscosity data and OLI prediction data in Table 4-5 is compared against data from earlier solubility testing ${ }^{11}$ in $^{2}$ Figure 4-8. The experimental data includes two intermediate points (20 and 40 process volumes) and the saturated sample at 55 process volumes. The intermediate samples from Experiment \#2 (magenta squares) are in very good agreement with the intermediate samples measured as part of the solubility report (blue triangles).

A comparison of the OLI viscosity data with experimental data shows some agreement, but not very good agreement. Figure 4-8 indicates that the trend of the OLI model data is similar to that of the experimental data. The absolute values for the model data are somewhat higher than the experimental data, although within the range of all earlier viscosity data. The reason for the difference between the OLI model and experimental data is unclear. The effect of differences in total acidity between the two data sets is unknown.

\subsubsection{Heat Capacity and Thermal Conductivity}

Heat capacity and OLI prediction data in Table 4-5 is compared against data from earlier solubility testing ${ }^{11}$ in Figure 4-9. The experimental data includes four intermediate points (10, 20, 30 and 40 process volumes) and the saturated sample at 50 and 55 process volumes. Although the data from Experiment \#2 appears to be consistent within it, little agreement can be observed between the Experiment \#2 data and earlier solubility report data. The only consistency between the data sets is that the slope of the Experiment \#2 data (red squares) is similar to that of the solubility report data (blue triangles).

A comparison of the TFL AZ-102 heat capacity data from the OLI model (green circles) with experimental data shows reasonable agreement with the trend of the data reported for solubility testing (dark blue diamonds). The data from the TFL AZ-102 evaporation test yields a line with a slope similar to that of the model data, but the absolute

${ }^{11}$ R. A. Pierce and T. B. Edwards. "Cesium Eluate Evaporation Solubility and Physical Property Behavior," WSRC-TR-2002-00273, dated June 11, 2002. 


\section{WSRC-TR-2002- 00411, Rev. 0 \\ SRT-RPP-2002-00206}

values exhibit a significant offset. Significant differences between the different data sets suggests that a component of the difference is error in the analytical technique used for measuring heat capacity.

Figure 4-8. Viscosity Data Comparisons

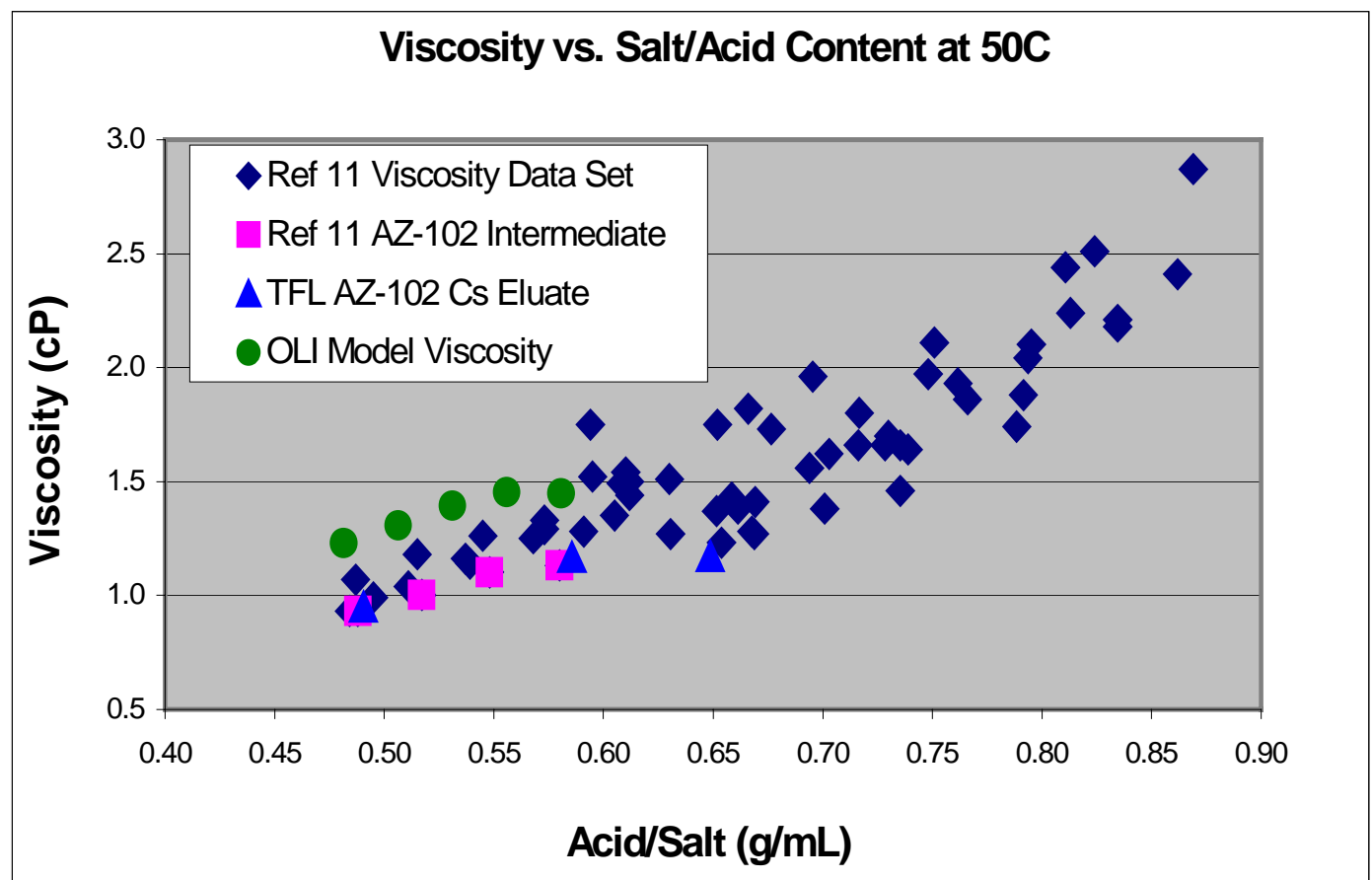

Figure 4-9. Heat Capacity Data Comparisons

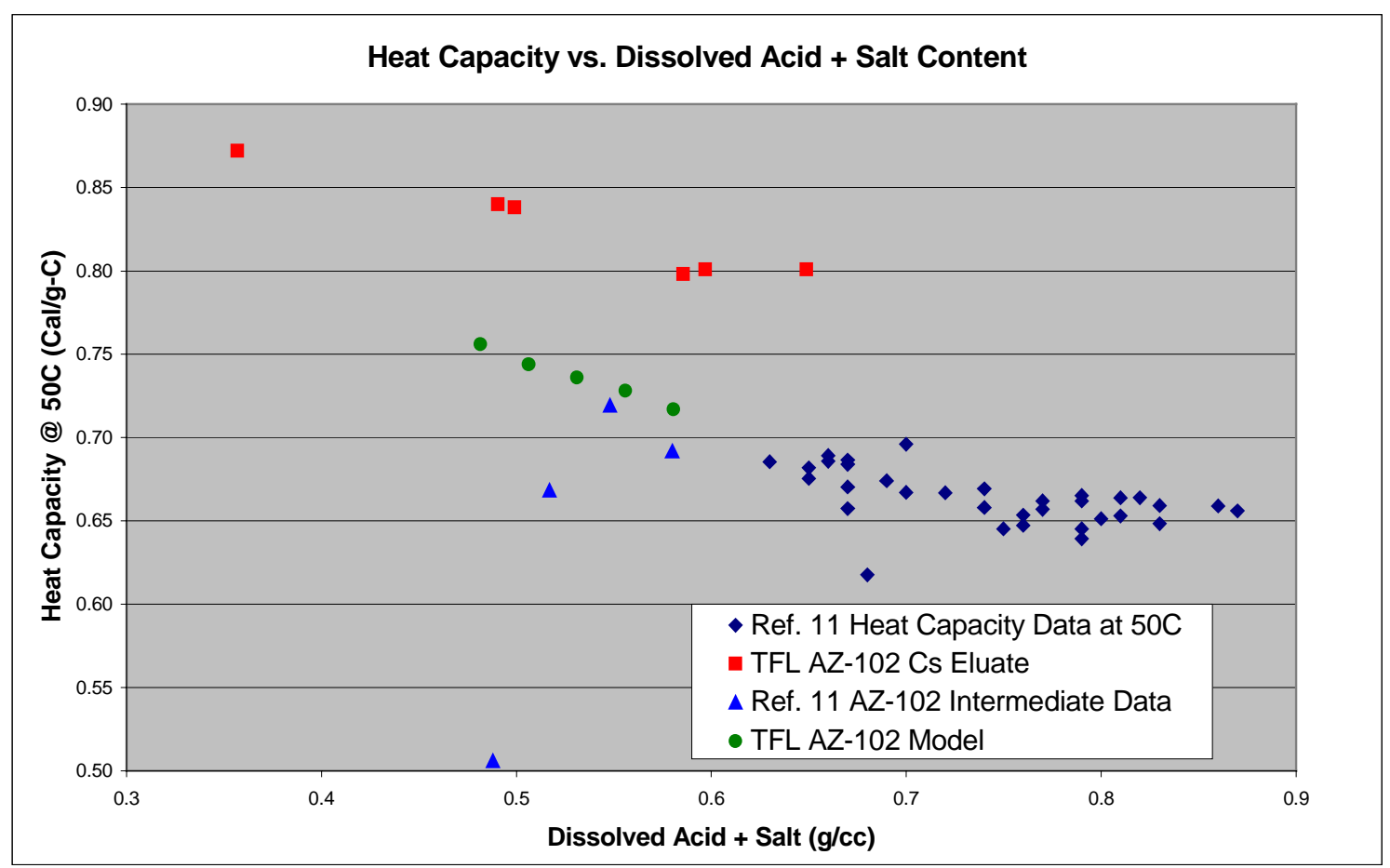


In a similar way, thermal conductivity and OLI prediction data in Table 4-5 is compared against data from earlier solubility testing ${ }^{11}$ in Figure 4-10. As in the solubility experiments, the amount of the scatter in the data is great and no meaningful conclusions can be drawn other than the analytical technique is not reliable. The fact that both the heat capacity and thermal conductivity data are inconsistent is not surprising since both measurements use essentially the same thermal response data.

Figure 4-10. Thermal Conductivity Data Comparison

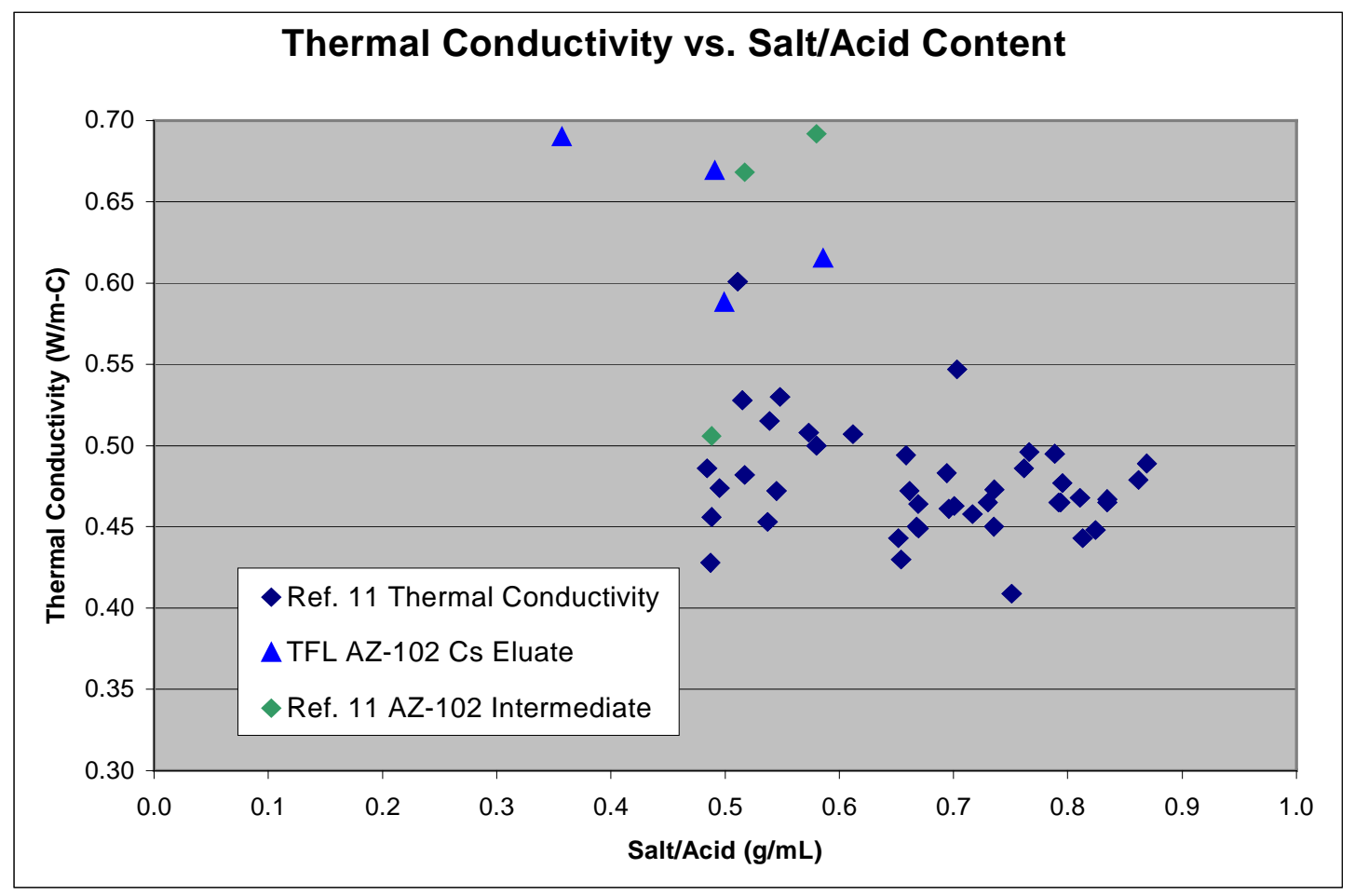

\subsubsection{Boiling Point}

Boiling point predictions from the OLI model were also compared against those measured during Experiment \#1. Prior to testing, the effectiveness of such a measurement was verified using two known solutions - water and 37.2 wt. $\% \mathrm{HNO}_{3}\left(7.25 \mathrm{M} \mathrm{HNO}_{3}\right)$. The behavior measured during testing is compared with data in the literature in Figure 4-11. Figure 4-11 shows that it is possible to collect accurate boiling point data within $1-2^{\circ} \mathrm{C}$ for pressures ranging between 100 and 300 torr.

Comparison of the OLI prediction at 70 torr for the experiments agrees with the observed boiling point. The expected boiling temperature, based on the model, is $55^{\circ} \mathrm{C}$. In Experiment $\# 1$ the boiling point varied from $55-58^{\circ} \mathrm{C}$. The boiling point for Experiment \#2 was measured at $54-55^{\circ} \mathrm{C}$ for process volumes $15-55$.

Other boiling point data was collected during Experiment \#1. After each 7 process volumes, the boiling point was measured at 150+/-10 torr and 300+/-10 torr. Where necessary, the pressure measurements were rounded for the purpose of listing the data (Table 4-6); the actual measured pressure values have been plotted (Figure 4-12). The data are also compared against OLI predictions in Table 4-6 and Figure 4-12.

The first observation made from Figure 4-12 is that the lines for the measurements are almost all parallel. This suggests that the boiling point readings were taken at or near steady-state. Also worth noting is that among the range of measurements, all but two of the sets ( 28 and 42 process volumes) show good agreement with the OLI predictions. 
Figure 4-11. Method Validation and Literature Values

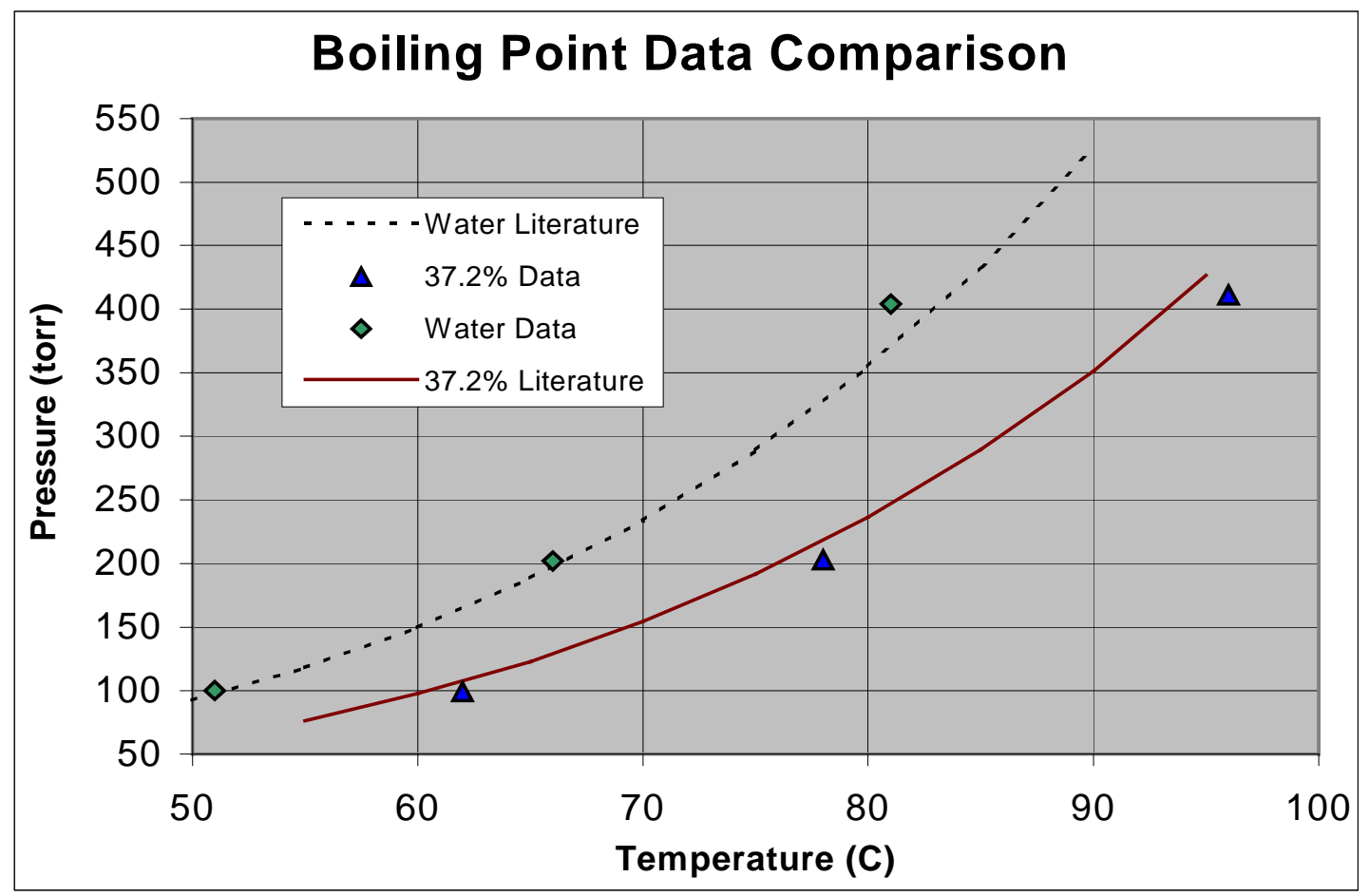

The discontinuity at 28 process volumes is of particular interest because this corresponds with the observed reduction of free acid (relative to total acid) and a local minimum in the density data in Figure 4-5. This is of particular importance because the boiling point data is from Experiment \#1 while the free acid and density data are from Experiment \#2. As discussed in Section 4.3.1.1, the reason for the observed behavior is not clearly understood. To a lesser degree, it might be possible to link the boiling point behavior at 42 process volumes to a less-noticeable rise in the density data (Figure 4-4), but this would seem to be much more speculative. 
Table 4-6. OLI and Experimental Boiling Point Data

\begin{tabular}{|c|c|c|c|}
\hline OLI MODEL PREDICTIONS \\
\hline \multirow{2}{*}{$\begin{array}{c}\text { Pressure } \\
\text { (torr) }\end{array}$} & \multicolumn{3}{|c|}{$\begin{array}{c}\text { Boiling Point } \\
\text { Reduction Factor of }\end{array}$} \\
\cline { 2 - 4 } & $\sim \mathbf{0}$ & $\mathbf{2 5}$ & $\mathbf{5 0 . 8}$ \\
\hline 140 & 67.5 & 66.9 & 66.9 \\
\hline 150 & 69.0 & 68.4 & 68.4 \\
\hline 160 & 70.6 & 70.0 & 70.0 \\
\hline 275 & 83.5 & 82.9 & 82.7 \\
\hline 300 & 85.7 & 85.1 & 84.9 \\
\hline 325 & 87.7 & 87.1 & 86.9 \\
\hline \multicolumn{4}{|c}{} \\
\hline
\end{tabular}

\section{EXPERIMENT \#1 MEASUREMENTS}

\begin{tabular}{|c|c|c|c|c|c|c|c|c|}
\hline $\begin{array}{c}\text { Pressure } \\
\text { (torr) }\end{array}$ & \multicolumn{7}{|c|}{ Boiling Point $\left({ }^{\circ} \mathbf{C}\right)$ at Volume Reduction Factor of } \\
\cline { 2 - 9 } & $\mathbf{7}$ & $\mathbf{1 4}$ & $\mathbf{2 1}$ & $\mathbf{2 8}$ & $\mathbf{3 5}$ & $\mathbf{4 2}$ & $\mathbf{4 9}$ & $\mathbf{5 6}$ \\
\hline 140 & 70.3 & & & & & & & \\
\hline 150 & & 73.0 & & & 71.4 & & & \\
\hline 160 & & & 72.8 & 64.1 & & 76.3 & 72.1 & 70.6 \\
\hline 290 & & & & & 88.4 & & & \\
\hline 300 & 85.7 & & 89.6 & 80.4 & & 92.1 & & \\
\hline 310 & & 90.7 & & & & & 88.5 & 84.3 \\
\hline
\end{tabular}

Figure 4-12. Boiling Point Data Comparison

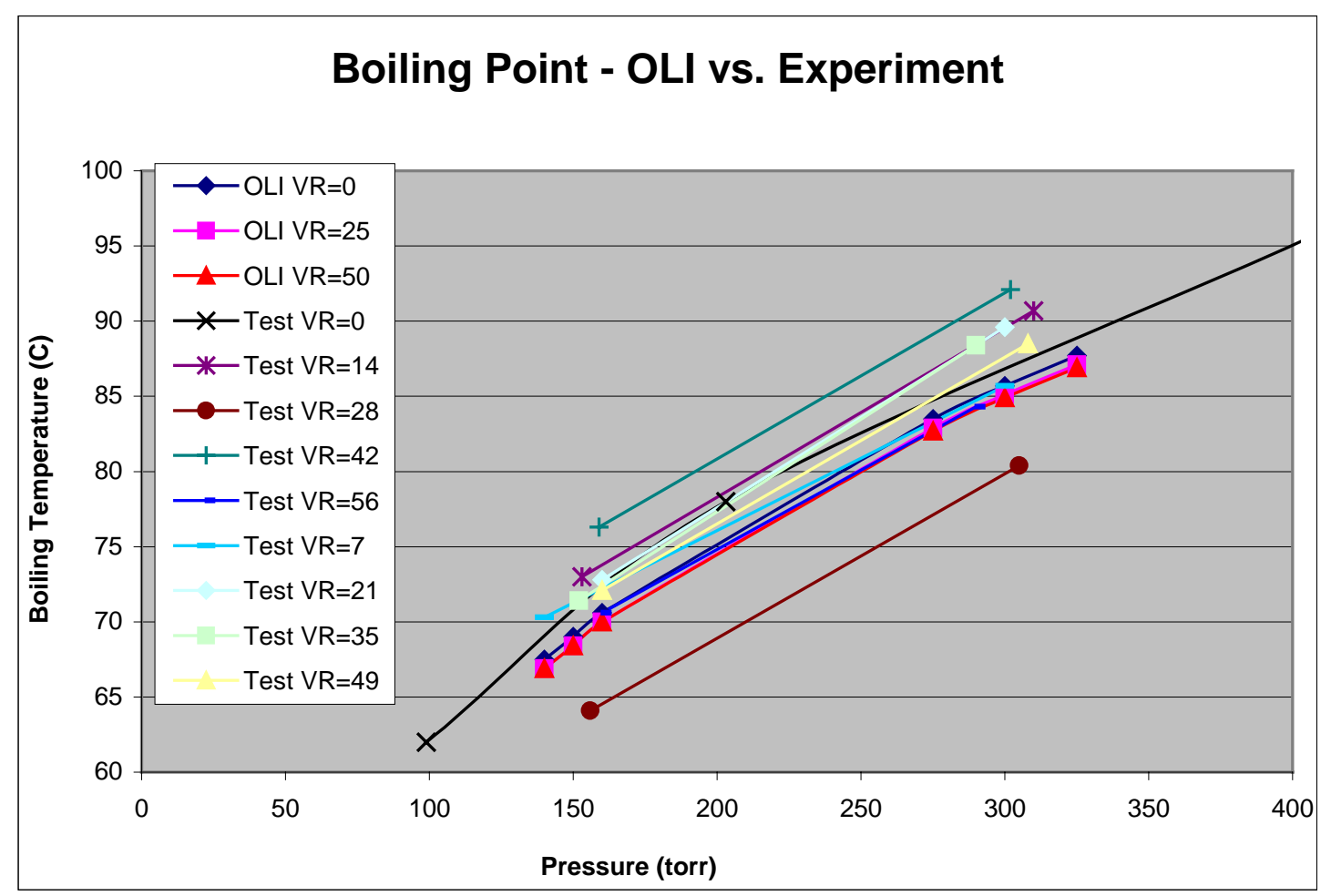




\subsection{EXPERIMENTAL DATA - CONDENSATE}

Analyses of condensate collected throughout the tests reveal very important information. The data are contained in Table 4-7 and Table 4-8. Of greatest importance is that experimental data correlate with the behavior predicted with the OLI model. The OLI model predicted a cumulative acid concentration of $0.57 \mathrm{M}$ for each experiment. Experiment \#1 produced a cumulative condensate of $0.599 \mathrm{M}$. The data is in good agreement, especially considering that the system was depressurized after each process volume. In Experiment \#2, the system was depressurized and condensate collected after each five process volumes. The cumulative acid concentration for the entire test was $0.468 \mathrm{M}$. However, as discussed in Section 4.3.1.2, the effect of the first 10 process volumes should be disregarded because of an experimental anomaly. The cumulative acid concentration for process volumes 11-55 was $0.560 \mathrm{M}$.

Another important observation made throughout the experiments was that the performance of the conductivity probe for acid concentration measurement was accurate and reliable. This is demonstrated best in Tables 4-7 and 4-8. Table 4-7 shows a comparison of probe test data from Experiment \#2 compared with titration data. Both shown excellent agreement. Table 4-8 also exhibits the accuracy of the probe. After the evaporation of each process volume, the acidity of each condensate sample was analyzed individually. At the end of the day (14 process volumes), the condensate for the entire day was combined and analyzed. In spite of fluctuations in condensate acidity from sample to sample, the mathematical average shows excellent agreement with the measured composite. Over the testing period, no adjustments were made to the conductivity probe, yet the probe response remained steady. The calibration data (Table 4-9) shows that the response of the system is consistent over long periods of time. The conductivity probe has the added benefit of being a simple analysis method with little or no opportunity for operator error.

Analyses of the four cumulative condensate samples from Experiment \#1 demonstrate that the amount of cation carryover from the evaporator to the condensate is low. The data also show halide concentrations less than $20 \mathrm{mg} / \mathrm{L}$ for individual analytes. Some TOC and TIC are observed, although not in very high concentrations (TOC/TIC in the concentrate is addressed in Section 4.1). Attempts to analyze for specific volatile or semi-volatile organic compounds were not made. Analyses of the concentrate, which have higher concentrations of TOC and TIC, did not identify any measurable quantities of volatile or semi-volatile organic compounds. The concentrations of other analytes are consistent with what was expected.

Table 4-7. Experiment \#2 Condensate Data

\begin{tabular}{|c|c|c|c|c|}
\hline $\begin{array}{l}\text { Process } \\
\text { Volumes }\end{array}$ & Acidity (M) & \\
\hline $1-5$ & 0.018 & \multicolumn{3}{|c|}{ Calculations } \\
\hline $6-10$ & \multicolumn{4}{|l|}{0.099} \\
\hline $11-15$ & \multicolumn{4}{|l|}{0.337} \\
\hline $16-20$ & \multicolumn{4}{|l|}{0.524} \\
\hline $21-25$ & \multicolumn{4}{|l|}{0.661} \\
\hline $26-30$ & \multicolumn{4}{|l|}{0.640} \\
\hline $31-35$ & \multicolumn{4}{|l|}{0.528} \\
\hline $36-40$ & \multicolumn{4}{|l|}{0.614} \\
\hline $41-45$ & 0.629 & \multicolumn{3}{|c|}{ Average Condensate (1-55 Volumes) $=0.468 \mathrm{M}$} \\
\hline $46-50$ & 0.519 & \multicolumn{3}{|c|}{ Average Condensate (11-55 Volumes) $=0.560 \mathrm{M}$} \\
\hline $51-55$ & 0.586 & & & \\
\hline $\begin{array}{c}\text { Day \# } \\
\text { Condensate }\end{array}$ & \multicolumn{2}{|c|}{$\begin{array}{c}\text { Probe } \\
\text { Acidity (M) }\end{array}$} & $\begin{array}{c}\text { Titrated } \\
\text { Acidity (M) }\end{array}$ & \\
\hline 1 & \multicolumn{2}{|c|}{0.058} & 0.061 & \\
\hline 2 & \multicolumn{2}{|c|}{0.431} & 0.420 & \\
\hline 3 & \multicolumn{2}{|c|}{0.650} & 0.647 & \\
\hline 4 & \multicolumn{2}{|c|}{0.571} & 0.559 & \\
\hline 5 & \multicolumn{2}{|c|}{0.578} & 0.573 & \\
\hline
\end{tabular}


Table 4-8. Experiment \#1 Condensate Data

\begin{tabular}{|c|c|c|c|c|c|c|c|}
\hline $\begin{array}{l}\text { Process } \\
\text { Volume }\end{array}$ & Acid (M) & $\begin{array}{l}\text { Process } \\
\text { Volume }\end{array}$ & Acid (M) & $\begin{array}{l}\text { Process } \\
\text { Volume }\end{array}$ & Acid (M) & $\begin{array}{l}\text { Process } \\
\text { Volume }\end{array}$ & Acid (M) \\
\hline 1 & 0.914 & 15 & 0.581 & 29 & 0.476 & 43 & 0.713 \\
\hline 2 & 0.744 & 16 & 0.582 & 30 & 0.472 & 44 & 0.686 \\
\hline 3 & 0.631 & 17 & 0.603 & 31 & 0.561 & 45 & 0.593 \\
\hline 4 & 0.550 & 18 & 0.544 & 32 & 0.529 & 46 & 0.805 \\
\hline 5 & 0.416 & 19 & 0.604 & 33 & 0.464 & 47 & 0.734 \\
\hline 6 & 0.469 & 20 & 0.501 & 34 & 0.564 & 48 & 0.730 \\
\hline 7 & 0.461 & 21 & 0.515 & 35 & 0.402 & 49 & 0.700 \\
\hline 8 & 0.642 & 22 & 0.629 & 36 & 0.569 & 50 & 0.439 \\
\hline 9 & 0.624 & 23 & 0.647 & 37 & 0.598 & 51 & 0.466 \\
\hline 10 & 0.578 & 24 & 0.735 & 38 & 0.680 & 52 & 0.594 \\
\hline 11 & 0.711 & 25 & 0.769 & 39 & 0.733 & 53 & 0.614 \\
\hline 12 & 0.764 & 26 & 0.478 & 40 & 0.651 & 54 & 0.616 \\
\hline 13 & 0.673 & 27 & 0.437 & 41 & 0.641 & 55 & 0.471 \\
\hline 14 & 0.537 & 28 & $\underline{0.384}$ & 42 & 0.555 & 56 & 0.533 \\
\hline Average & 0.622 & & 0.572 & & 0.564 & & 0.621 \\
\hline Cumulative & 0.629 & & 0.582 & & 0.563 & & 0.623 \\
\hline \multicolumn{2}{|l|}{ Measured } & \multicolumn{6}{|c|}{ Average Condensate $(1-56$ Volumes $)=0.599 \mathrm{M}$} \\
\hline & & & \multirow{3}{*}{\begin{tabular}{|l}
15 to 28 \\
Volumes \\
\end{tabular}} & \multirow{3}{*}{$\begin{array}{l}29 \text { to } 42 \\
\text { Volumes }\end{array}$} & \multirow{3}{*}{$\begin{array}{l}43 \text { to } 56 \\
\text { Volumes }\end{array}$} & & \\
\hline & & 1 to 14 & & & & & \\
\hline & Analyte & Volumes & & & & & \\
\hline & $\mathrm{Na}$ & 11 & 40.7 & 13.6 & 10.9 & & \\
\hline & $\mathrm{Al}$ & 4.22 & 3.67 & 4.37 & 4.25 & & \\
\hline & $\mathrm{Ca}$ & 0.83 & 0.94 & 0.82 & 0.78 & & \\
\hline & $\mathrm{Cr}$ & $<.05$ & 1.26 & 0.11 & $<.05$ & & \\
\hline & $\mathrm{Cu}$ & $<.05$ & 0.1 & $<.05$ & $<.05$ & & \\
\hline & $\mathrm{Fe}$ & 0.06 & 0.19 & 0.07 & 0.1 & & \\
\hline & NO3 & 35500 & 30000 & 31200 & 28700 & & \\
\hline & $\mathrm{F}$ & $<20$ & $<20$ & $<20$ & $<20$ & & \\
\hline & $\mathrm{Cl}$ & $<20$ & $<20$ & $<20$ & $<20$ & & \\
\hline & SO4 & $<50$ & $<50$ & $<50$ & $<50$ & & \\
\hline & $\mathrm{PO} 4$ & $<100$ & $<100$ & $<100$ & $<100$ & & \\
\hline & $\mathrm{C} 2 \mathrm{O} 4$ & $<100$ & $<100$ & $<100$ & $<100$ & & \\
\hline & TOC & 15.7 & 13.9 & 14.6 & 17.4 & & \\
\hline & TIC & 10.7 & 10.1 & 10 & 10 & & \\
\hline
\end{tabular}

Table 4-9. Conductivity Probe Calibration Data

\begin{tabular}{|c|c|c|c|}
\hline $\begin{array}{c}\text { Known } \\
\text { Acidity }(\mathrm{M})\end{array}$ & $\begin{array}{c}\text { Probe Data on } \\
7 / 15 / 02(\mathrm{mS})\end{array}$ & $\begin{array}{c}\text { Probe Data on } \\
7 / 29 / 02(\mathrm{mS})\end{array}$ & $\begin{array}{c}\text { Probe Data on } \\
8 / 9 / 02(\mathrm{mS})\end{array}$ \\
\hline 0.262 & 86.9 & 86.4 & 86.8 \\
\hline 0.524 & 168.4 & 167.5 & 167.7 \\
\hline 0.774 & 238.3 & 239.0 & 237.6 \\
\hline
\end{tabular}




\subsection{CONCLUSIONS}

Two experiments have been performed with a TFL-generated AZ-102 cesium eluate simulant. The data from the experiment has been compared with predictions from the OLI model. The predictions of the OLI model show good agreement with experimental results. A plot of the OLI predictions with earlier solubility data showed excellent agreement between the model and experimental data. For the evaporation test, the OLI model predicted precipitation of $\mathrm{NaNO}_{3}$ at a concentration factor of 50. Evaporation experiments yielded bulk precipitation of $\mathrm{NaNO}_{3}$ at a concentration factor of 51-55. Trace amounts of precipitate formed at concentration factors of 41-45 and 46-50 after several days. The difference between the model results and the evaporation data can be attributed to wide fluctuations in measured total acidity for the evaporation test.

OLI model predictions of condensate acidity, boiling point, and sample density agree with evaporation data. The experimental data exhibits a local minimum at a concentration factor of 25-30 that is not predicted by the model. The local minimum in the density data corresponds with the reduction of free acid in the system and an apparent change in boiling point behavior. Viscosity predictions by OLI show some agreement with experimental data. The modeling data exhibit a trend comparable to experimental, but the absolution viscosity values for the OLI data are somewhat higher than the measured viscosity data. The reason for the difference is unknown.

A comparison of the evaporation data with earlier solubility and physical property studies also show good agreement. A plot of the experimental data with earlier solubility data for AZ-102 and sodium nitrate show that precipitation is expected at a concentration factor of 41-45. Density and viscosity data from the evaporation also agree with earlier physical property data. Heat capacity and thermal conductivity data exhibit some problems.

The evaporation experiments also demonstrated the performance of a conductivity probe in analyzing samples for acid concentration. Throughout the experiments the conductivity probe was accurate and reliable. In spite of fluctuations in condensate acidity throughout testing, calculated averages shows excellent agreement with the measured samples. The conductivity probe has the added benefit of being a simple analysis method with little or no opportunity for operator error. No resin fines were observed in the TFL AZ-102 eluate fed to the evaporator. Foaming problems were not encountered during evaporation.

\subsection{ISSUES \& RECOMMENDATIONS}

Fluctuations in total acid measurements make it difficult to correlate experimental data with OLI model. Both the OLI model prediction and the evaporation experiment agree with earlier solubility data without producing identical evaporation behavior. It is not clear if the fluctuations are a product of experimental technique or chemical behavior. In addition to the fluctuations, attempts to perform a material balance around total acid show that the measurement of total acid does not agree with what is expected based on condensate acidity. No definitive explanation is available, but it is expected that the formation of cation complexes with acid greatly affect the solubility behavior of the system.

Because of the importance of correlating experimental data with the OLI model predictions, it is recommended that several additional semi-batch experiments be performed. It is anticipated that these can be performed as part Tests Scoping Statements S-82 and S-86. 